\title{
Estimating adoption and impacts of agricultural management practices in developing countries using satellite data. A scoping review
}

\author{
Christoph Kubitza $^{1,2}$ (D) Vijesh V. Krishna ${ }^{2} \cdot$ Urs Schulthess $^{3} \cdot$ Meha Jain $^{4}$
}

Accepted: 28 January 2020 / Published online: 23 April 2020

(C) INRAE and Springer-Verlag France SAS, part of Springer Nature 2020

\begin{abstract}
Development and dissemination of sustainable practices are key to enhance agricultural productivity in developing countries and to curtail potential negative externalities. Rigorous adoption/impact evaluations provide valuable lessons to enhance the capacity of agricultural research-for-development (R4D) systems in this context. Conventional evaluation studies rely solely on farmhousehold surveys for data. Generation of survey data however requires considerable financial and human capital, and the process often misses several important explanatory variables, ignores the longer-term impacts, and suffers from measurement errors. Complementary data sources are explored to make the evaluations more robust and rigorous. Here we review 54 studies that used satellite data to estimate adoption and impact of agricultural practices in developing countries. Some evidence on successful application of satellite data in high-income countries is also provided. The main findings of the paper are threefold: (1) satellite data have been successfully used to detect agricultural practices, such as cropping intensity, tillage, crop residue cover, irrigation, and soil and water conservation; (2) only a few studies have estimated the yield impacts of agricultural practices, although the estimation of crop yields with satellite data is fairly developed; and (3) only a small number of studies have explored impact estimation beyond the biophysical sphere. Estimation of certain environmental impacts of agricultural practices is possible through satellite data, although only a few studies have carried it out. Not many have assessed the economic impacts of interventions. We conclude that satellite data analysis allows information access with little delay and over longer periods, provide a unique set of variables over wide geographies, and reduce measurement error in certain variables. However, more interdisciplinary research is necessary to speed up the uptake of this alternative data source in R4D evaluations.
\end{abstract}

Keywords Remote sensing $\cdot$ Agricultural practices $\cdot$ Impact evaluation $\cdot$ Developing countries

Contents

1. Introduction

2. Study selection

Christoph Kubitza

christophkubitza@posteo.de

1 Department of Agricultural Economics and Rural Development, University of Goettingen, 37037 Goettingen, Germany

2 Socio-Economics Program, International Maize and Wheat Improvement Center (CIMMYT), 56237 Texcoco, Mexico

3 CIMMYT-Henan Collaborative Innovation Center, Henan Agricultural University, Zhengzhou 450002, People's Republic of China

4 School for Environment and Sustainability, University of Michigan, Ann Arbor, MI 48109, USA
3. Measuring diffusion of agricultural practices

3.1. Cropping intensity

3.2. Tillage and crop residue cover

3.3. Irrigation

3.4. Soil and water conservation

3.5. Identifying crop types

4. Measuring crop yield and yield effects

4.1. Measuring crop yield

4.2. Measuring yield effects

5. Measuring environmental and economic outcomes

5.1. Measuring environmental outcomes

5.2. Measuring economic outcomes

6. Future prospects

7. Conclusion

Acknowledgments

References 


\section{Introduction}

Growth in agricultural productivity and reduction in rural poverty are inextricably linked with investment in research and development (R\&D) in agriculture (Evenson and Gollin 2003; Pray et al. 2017). However, the funding for agricultural R\&D has become scarce globally (Hurley et al. 2014; Raitzer and Maredia 2012). There is also an increasing need to verify whether the R\&D investments generate positive impacts on system productivity and rural livelihoods and to learn from the completed R\&D activities. Measuring progress towards national and international development goals such as the SDGs (Sustainable Development Goals) has also become fundamental to coordinate global action in the face of poverty and climate change and further to improve the nature and type of interventions. Socioeconomic studies on farmer acceptance of technologies and the resulting changes in farming system productivity and economic and social welfare play a critical role in the evaluation process. While the number of technology assessment studies has been growing, the approach these studies have followed to measure the impact of interventions has limitations and has remained largely unchanged over time.

The conventional approach to study farmer adoption of agricultural technologies and their impacts are often solely based on data from detailed face-to-face farm-household surveys. While the derived information is valuable, the procedure requires considerable financial and human resources. Furthermore, the time gap between commissioning a field survey and disseminating the findings is often too large to allow for timely corrective actions in project implementation. The conventional approach is also criticized for limited sample sizes and statistical power (Ioannidis et al. 2017), for not measuring longer term impacts (Pittelkow et al. 2015), and for ignoring the potential spillover effects of the technology (LeSage and Pace 2009). There is also evidence that there is significant measurement error in farmer reports of certain variables, including yield, which may lead to inaccurate impact estimates of interventions (Burke and Lobell 2017; Carletto et al. 2013). These criticisms are valid, and hence it is necessary to look for comprehensive but easy-to-capture datasets to complement the current evaluation approach. Here we propose that integrating satellite data into studies that measure technology adoption and the impacts of interventions can overcome some of these limitations. Unlike other development interventions (e.g., in health), farmers' adoption and spread of agricultural practices, for instance changes in cropping intensity, tillage, or irrigation, can be remotely sensed. In Fig. 1, we present two examples - land preparation using reduced tillage and the diffusion of maize cultivationthat can be detected using satellite data. Furthermore, some of the impacts of agricultural practices (e.g., yield increases and environmental effects) can also be estimated through satellite data. Eventually, the associated economic outcomes can be a
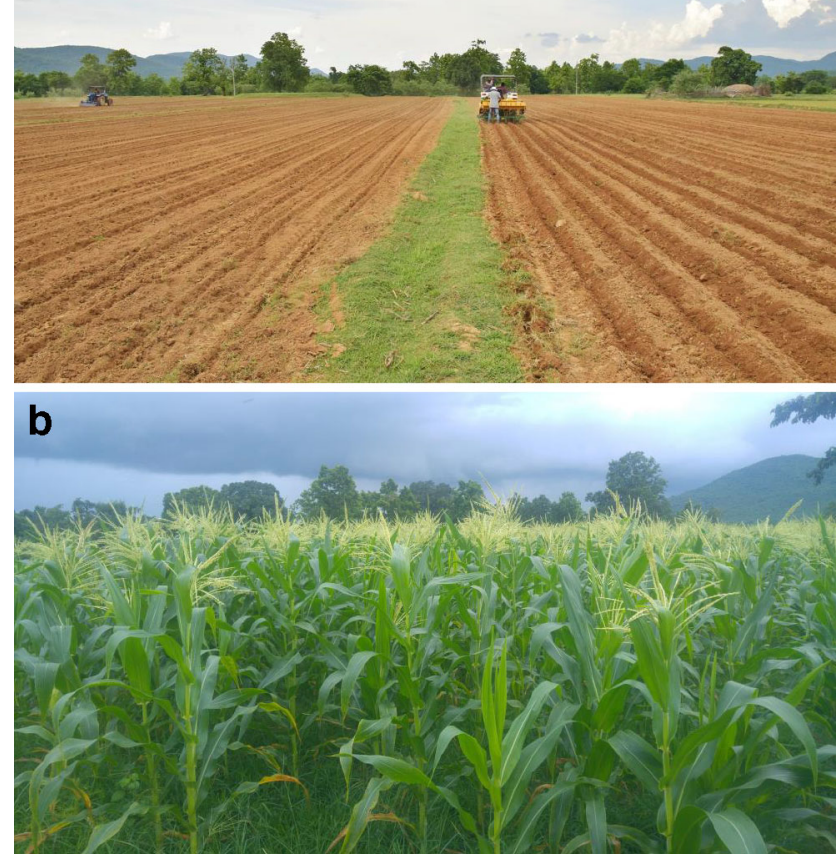

Source: Photograph a provided by Wasim Iftikar. Photograph b provided by authors.

Fig. 1 Changes in agricultural practices can be detected using satellite data. a Land preparation; b Crop type

also tracked through satellite data at larger scales (e.g., changes in roof structures, density and length of roads, and nighttime lights). This underlines the relevance of satellite data in the field of adoption/impact estimation of technological interventions in agriculture, particularly against the backdrop of recent advancements in remote sensing.

Access and availability of satellite data have increased rapidly over the last decades, driven by recent milestones such as the launches of Sentinel satellites as well as plummeting costs of space transportation and the development of microsatellites. At the same time, the minimum spatial resolution decreased from $80 \mathrm{~m}$ to about $1 \mathrm{~m}$ for multispectral sensors (see Table 1 ). Computational power has also increased exponentially, providing researchers with the means to process the available information quickly and more efficiently. Subsequent to these developments, various applications of satellite data emerged, which include identification of changes in agricultural practices and related economic outcomes remotely from the space (Bégué et al. 2018; Donaldson and Storeygard 2016). The relevance of satellite data is threefold, as compared with the conventional approach using farm-household survey data. One, satellites facilitate generation of data over time, providing critical panel data that can generate baselines even before commissioning of a project, and thus allow researchers to measure the impact of an intervention through time. Two, they 


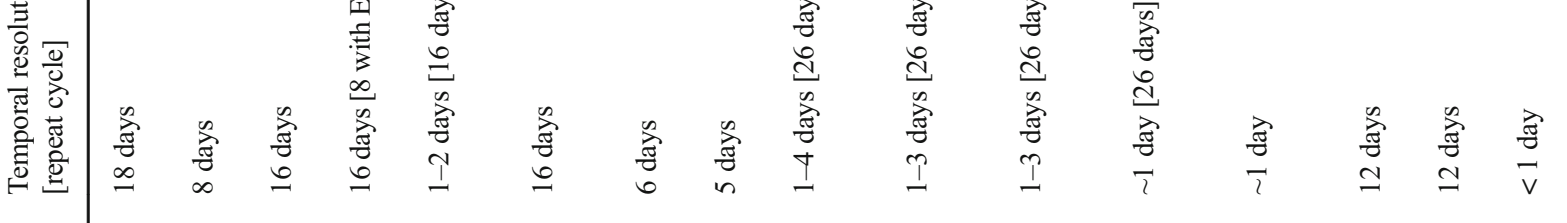

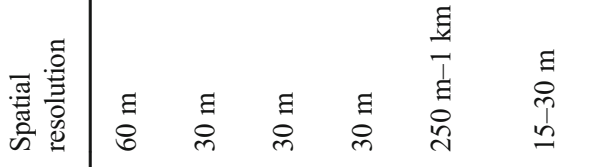

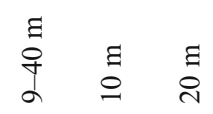

$\stackrel{4}{2}$

๕

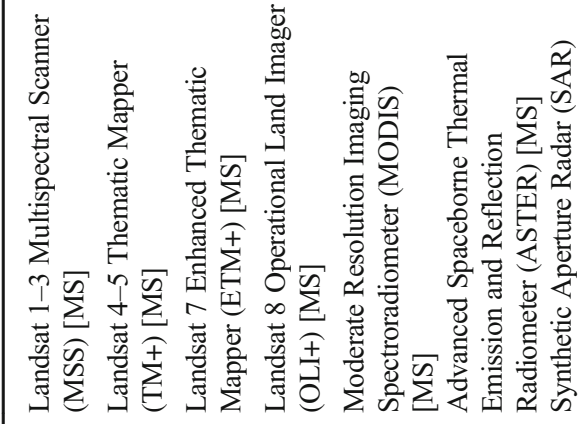

寻早

峞崩

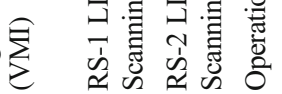
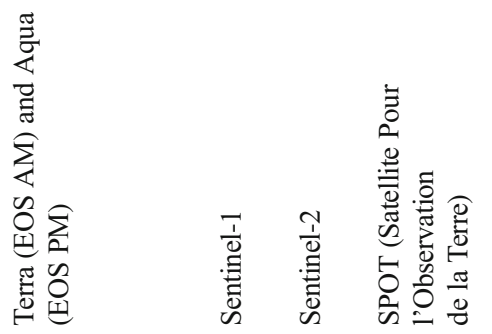


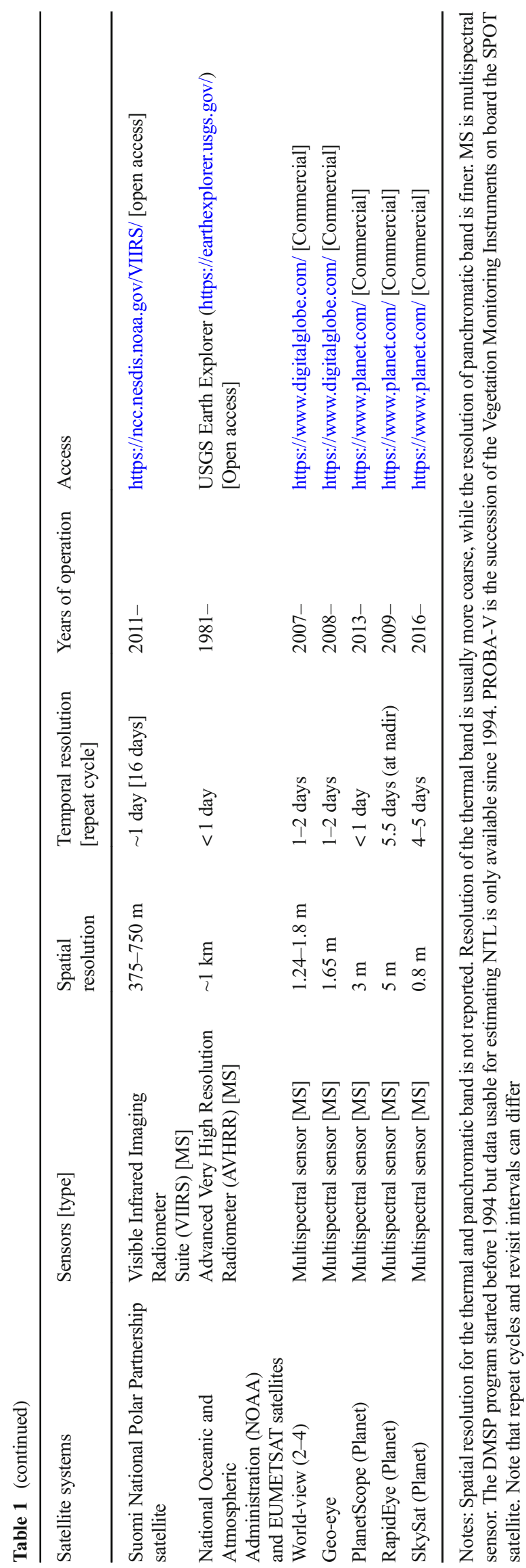

provide access to a unique set of observations on agricultural practices and their respective impacts over a wide geography, allowing one to do impact evaluation at large scales and measure potential spillover effects. Three, with increasing spatial, spectral, and temporal resolution, satellite imagery can increase the accuracy of estimating adoption rates of agricultural practices and their respective impacts. These points are briefly discussed below.

Satellite imagery provides data over long time periods for agricultural practices, crop types, and the respective outcome variables. For example, long-term satellite datasets allow researchers to identify crop characteristics in the study area over several years prior to the start of the intervention. Such historical data are difficult to generate through household surveys because of recall biases and changes in plot ownership as well as household heads (Kubitza et al. 2018). Furthermore, estimates of historical changes in cropping practices and crop types can be used to validate assumptions of impact models (e.g., assumption of parallel trends in difference-in-difference estimation). Lastly, satellite data can enable researchers to track outcomes of interventions over long-time frames without investing additional time and money on follow-up surveys. This allows researchers to examine the adoption dynamics (e.g., continuous versus intermittent adoption) of technologies on farmers' fields and the impacts of the technology on yield, crop type, and other variables of interest.

The second advantage of satellite data is the ability to measure variables of interest over large geographic areas. Many adoption-impact studies are limited in scope due to small sample size, which, in turn, is owing to the high costs of groundbased surveys and limited economies of scale. While multiple surveys may be conducted on the same intervention, combining datasets from different surveys is not always possible as survey instruments are often developed independently and often applied to different sample populations, resulting in non-uniform variable sets. Given that satellite data are freely available across the globe, widening the geographic coverage of measuring variables of interest using satellite data may involve only minor additional costs, which allows for increasing sample sizes and impact evaluations over large geographical areas. Such datasets would also allow for the evaluation of potential spillovers (e.g., impact of technology on nonadopters' plots), which have to be taken into account to assess the costs and benefits of interventions (Tsusaka et al. 2015; Wollni and Andersson 2014). Moreover, data on weather, land cover, soil quality, and even certain economic activities, such as infrastructure development that are sometimes difficult to elicit through household surveys, could be integrated into adoption and impact estimation, reducing biases from potential confounding variables.

Lastly, new satellite sensors deliver data at higher spatial, temporal, and spectral resolutions, which can increase the accuracy of measuring certain variables, including yield and 
crop type. This is especially critical in data-poor developing countries. For example, higher temporal resolution data provided by Sentinel-2 has been shown to increase the accuracy of mapping field-level crop types (Vuolo et al. 2018). In addition, finer spatial resolution data have been found to lead to more accurate field-level yield estimates in smallholder systems compared with coarser resolution products (Jain et al. 2016). These satellite-derived datasets may be more accurate than similar variables collected through household surveys. For instance, most regional estimates of crop productivity are crucially dependent on spatial information such as plot size. However, studies have shown that self-reported estimates of plot size have large measurement errors and biases compared with GPS-estimated field sizes (Burke and Lobell 2017; Carletto et al. 2013; Holden and Fisher 2013).

While there is a growing literature that has employed satellite datasets to examine changes in agricultural practices, these studies are scattered across disciplines and are not very easy to access for non-experts of remote sensing. Against this background, the present study aims to outline the potential applications as well as limitations of using satellite data in agricultural and development economic research, particularly for capturing changes in developing country's agriculture. We aim to reach both researchers and policy makers through providing a comprehensive, non-technical review on the current uses of satellite data to assess the adoption and impacts of agricultural practices. We explicitly focus on technological change in agriculture and stay clear of land cover changes, for instance agricultural expansion or deforestation, since such broader developments are a domain in their own right. Our geographical focus is on low- and middle-income countries. These countries are often data-poor and significantly differ from the industrialized countries in many ways, including fragmented plots, intercropping, and lack of precise groundtruth data (Burke and Lobell 2017). Moreover, farmers in developing countries typically have only limited access to agricultural expertise and technologies and often lack the ability to accurately estimate yields and plot sizes. While there are a few reviews on applications of satellite data to identify cropping practices (Bégué et al. 2018), tillage (Zheng et al. 2014), land cover (Gómez et al. 2016), and yield estimation (Chivasa et al. 2017), they focused on the technical aspects of remote sensing rather than on the possibilities of integrating satellite data into adoption and impact studies. Here we specifically discuss how typical estimation approaches and data types used by economists, such as econometric estimation using farm-household survey data, could be enhanced further through integrating satellite data.

The paper is structured as follows. In the next section, we briefly explain the strategy used to select the studies for this scoping review. In Section 3, we synthesize the relevant literature on current applications of satellite data to evaluate farmer adoption of agricultural practices. The applications of satellite data on measuring crop yield are reviewed in Section 4, and on measuring environmental and economic variables in Section 5. Section 6 discusses the future prospects of applying satellite data in technology evaluation studies. The last section concludes this paper.

\section{Study selection}

This study aims to highlight the ways in which satellite data can contribute to the existing knowledge base of adoption and impacts of changing agricultural practices in developing countries. We aim neither to undertake a formal meta-analysis of empirical findings nor to rate the quality of the studies. Instead, we focused solely on potential applications of satellite data. We searched databases covering agriculture, rural development, remote sensing, and economics, including peer-reviewed papers, working papers, and conference presentations. The databases include AgEcon, AGRIS, World Bank, GeoRef, Scopus, and IDEAS. The key words (including headings, subheadings, abstract, and keywords) searched for were "remote sensing," "satellite," "radar," or "LIDAR," in combination with “*crop*," "agricult*," "tillage," or "irrigation." The period ranged from 1972, when the first Landsat satellite had been launched, to December 2018. Titles and available abstracts were scanned for their relevance, articles requiring further consideration were shortlisted, and full papers were accessed. To reduce the risk of missing relevant papers, we searched the references of the collected articles and asked for paper suggestions from researchers from the field of remote sensing.

For this review, we included only those studies that were (a) assessing the uptake of agricultural practices and/or their yield or economic effects and (b) employing satellite data for the analysis. In other words, papers that at least partly focused on adoption and impacts using satellite data were included, but not the studies on methodological improvement (e.g., testing new sensors and indices). Studies were also not included if they were primarily using satellite data for illustrative purposes. Furthermore, we did not focus on studies identifying land cover changes such as changes in agricultural land area or deforestation since some reviews already exist (Gómez et al. 2016). We also did not include studies concerning weed infestation since applications in developing countries are scare and some reviews already exist (Fernández-Quintanilla et al. 2018). Our selection was restricted to manuscripts that were written in English. Besides qualitatively describing the papers, we systematically captured the topic of research, source of data (i.e. satellite program), research area, journal, and year of publication.

Overall, we found 54 studies that focused on assessing the adoption and impacts of agricultural practices using satellite data in developing countries. To delineate new potential applications of satellite data for adoption-impact studies in developing countries, we also reviewed studies that were (a) not 
directly related to adoption or impact but collected important outcome variables of interest such as yield and/or (b) conducted in high-income countries. In total, 88 studies were reviewed. Of the 54 studies related to adoption or impact and conducted in developing countries, most relied on satellite data from Landsat (25\%) and MODIS (28\%) due to their open access policy and availability of highly processed endproducts (see Fig. 2). The use of Sentinel 1 and 2 datasets has been gaining academic attention in the recent past, as has the use of high-resolution datasets from private companies, for instance DigitalGlobe and Planet.

Most of these studies were conducted in India (28\%), followed by China and Brazil (see Fig. 3). A small share $(11 \%)$ of the studies employed data from more than one country. Only a relatively small number of studies were conducted in South America, Sub-Saharan Africa (with the possible exception of Ethiopia), or Central Asia. Most studies were published in disciplinary journals of remote sensing. We found only three studies published in standard agricultural and development economics journals. In Table 2, we list the number of studies found according to the agricultural practices and outcome variables that were estimated by satellite data.

\section{Measuring diffusion of agricultural practices}

Agricultural productivity of low- and middle-income countries remains lower than in more industrialized nations, making efficient dissemination of new technologies a developmental priority. While new agronomic and breeding interventions frequently evolve out of different $R \& D$ endeavors, their adoption by farmers often remains well below the expectations (Doss 2006; Knowler and Bradshaw 2007). Gaining a better understanding of the potential constraints to adoption, as well as adapting agricultural technologies to farmer conditions (reinvention) are key components of applied agricultural research. In this section, we review the studies that assessed farmer adoption of agricultural practices, including cropping intensity, tillage, mulching, irrigation, and new crop types using satellite data.

\subsection{Cropping intensity}

Identification of cropping system intensification, defined conventionally as increasing land productivity over a given period of time (Gregory et al. 2002), is an important field of application of satellite data. The traditional view of intensification assumes that such an increase in productivity can be achieved through increased input use or number of crops per year, without any explicit concern about system sustainability. While satellite data have been frequently used to detect changes in cropping intensity (that is, increasing the number of crops per unit of land per unit of time), the task to categorize these changes as sustainable (or not) rests with the researchers. With remote sensing, cropping intensity is commonly identified by measuring changes in vegetation indices over time. The calculation of vegetation indices is based on exploiting
Fig. 2 Satellite programs and sensors used in the reviewed literature (1971-2018)

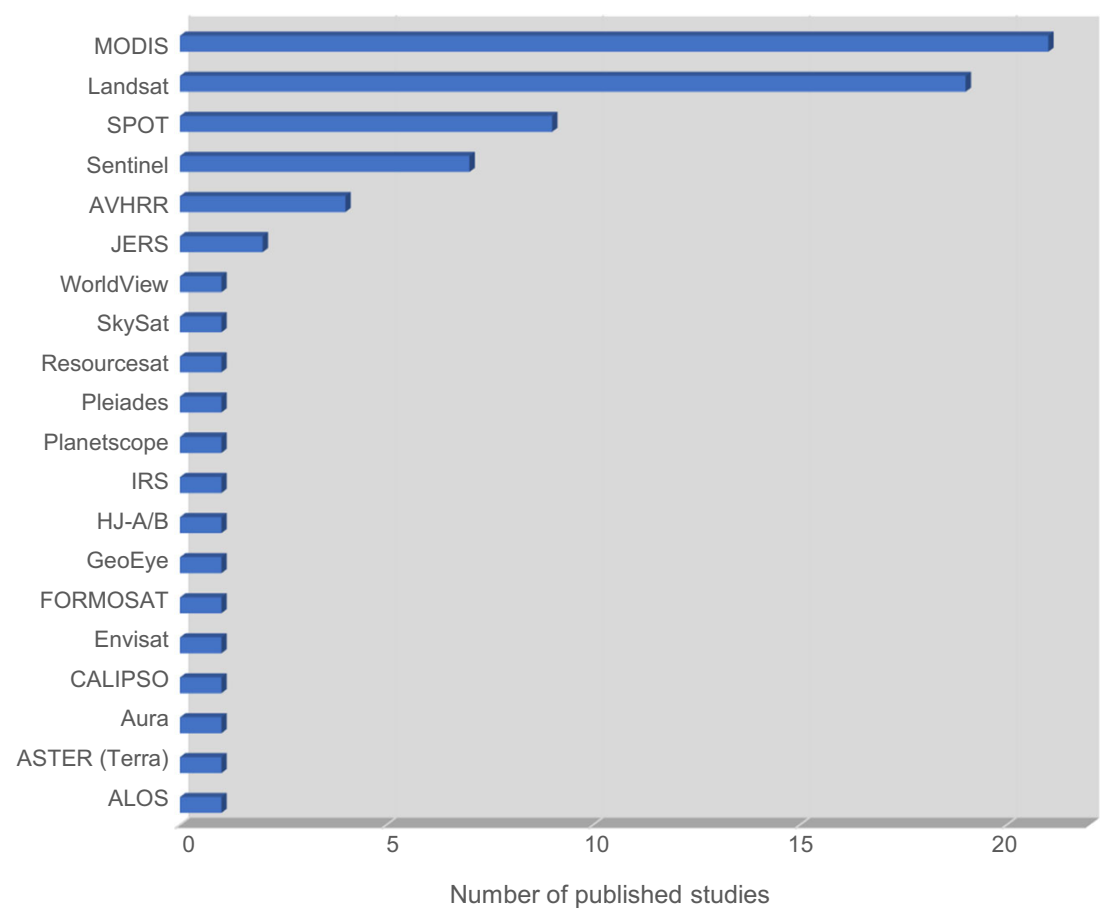

Notes: Only studies on adoption and impact of agricultural practices in low and middle-income countries are included $(\mathrm{N}=54)$. 
Fig. 3 Geographical coverage in the reviewed literature (19712018)

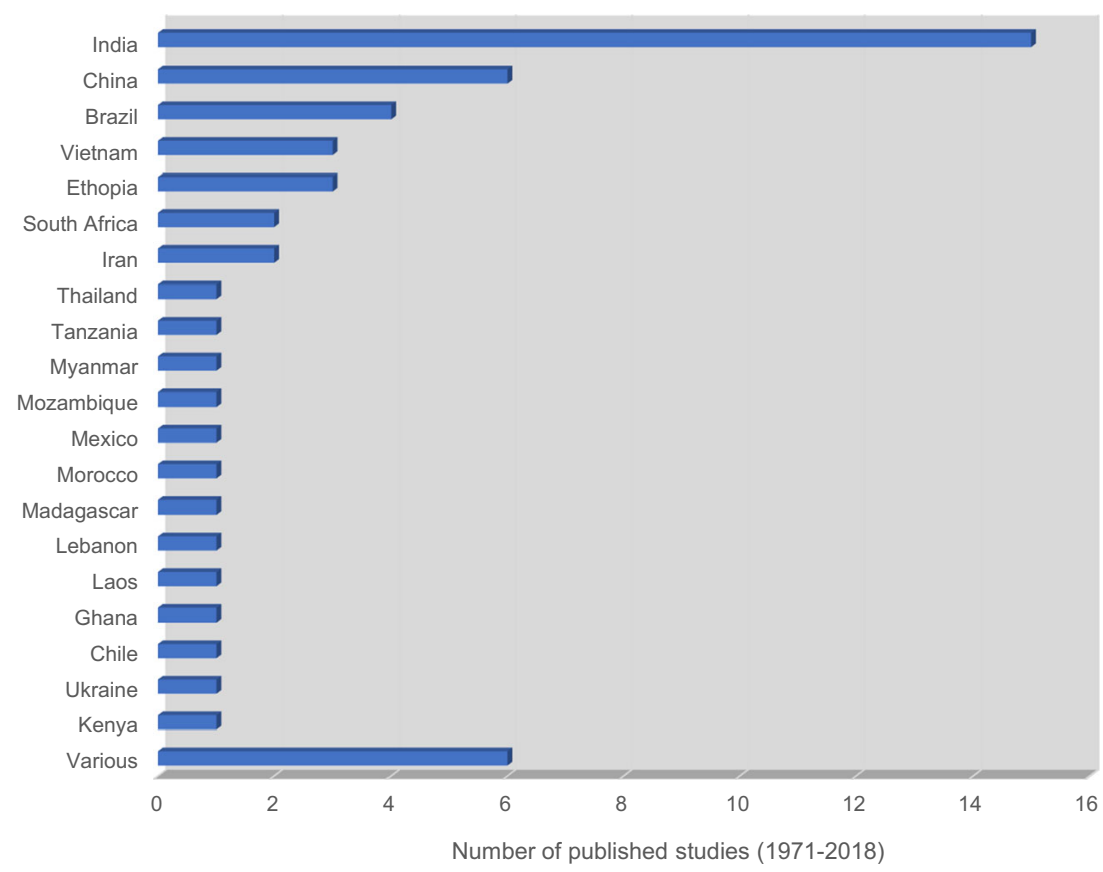

Notes: Only studies on adoption and impact of agricultural practices in low and middle-income countries are included $(\mathrm{N}=54)$. the unique reflectance of vegetation in the near-infrared and red spectral bands compared to other common land cover classes, for instance bare soil, water, and snow. Healthy vegetation strongly reflects near-infrared light, which is linked to high values in vegetation indices. To measure cropping intensity, researchers examine vegetation index phenologies or time series of vegetation indices and count the number of peaks in vegetation indices. This is because vegetation indices

Table 2 Use of satellite data in assessing adoption and impact of agricultural practices

\begin{tabular}{ll}
\hline & Number of studies included \\
\hline Adoption of agricultural practices & 9 \\
Cropping intensity & 1 \\
Crop succession & 2 \\
Tillage & 2 \\
Crop residue cover & 2 \\
Optimal sowing & 8 \\
Irrigation & 2 \\
Soil and water conservation measures & 14 \\
Crop types & \\
Impact of agricultural practices & 7 \\
Yield & 1 \\
Economic outcomes & 2 \\
Vegetation health & 5 \\
Air quality & \\
\hline
\end{tabular}

Notes: One study is double-counted as it examined both irrigation and tillage practices (Hadria et al. 2009) rapidly increase after sowing, reach a peak value towards the end of the growing season, and then decline at the end of the growing season due to senescence and harvest. For instance, two peaks in a vegetation index time series over the course of 1 year indicate two growing cycles in that year. Fallows often do not exhibit rapid changes in vegetation indices and can hence be distinguished. Obtaining such spectral profiles over time necessitates long-term satellite data with high temporal resolution such as from NOAA-AVHRR, SPOT, or MODIS. These datasets tend to be coarse in spatial resolution, at scales of $250 \times 250 \mathrm{~m}^{2}$ or greater. Another challenging task is to acquire sufficient cloud-free images in order to establish a timeseries of vegetation index values for individual pixels.

We identified six papers that map cropping intensity at a local scale. Wilken et al. (2017) analyzed spatiotemporal patterns of land use and cropping intensities in a catchment in South India. Data are derived from Landsat-7 ETM+ and Resourcesat-1. Jain et al. (2013) mapped cropping intensity in Gujarat and southeastern Madhya Pradesh, comparing different estimation techniques. Using high-resolution imagery from QuickBird-2 and WorldView-2 for validation, the study found that Landsat-5 TM and 7 ETM+ datasets performed well predicting cropping intensity (adjusted $\mathrm{R}^{2}$ of 0.71 ). The authors found significant differences between their estimates and census data of the Government of India, which were attributed to potential underreporting in the census data. However, while Landsat satellite data provided the most accurate results, MODIS data were more suitable for mapping cropping intensity over large spatial and temporal scales given limited availability of cloud free Landsat data (Jain et al. 2017a). For 
example, Brown et al. (2013), Bellón et al. (2018), and Kastens et al. (2017) mapped cropping intensity using MODIS data, focusing mainly on soybean systems in Brazil. Unlike studies that used multispectral sensors such as MODIS, radar can penetrate through cloud cover allowing to acquire imagery with higher temporal resolution and thus has a decisive advantage in regions with frequent cloud cover. Lasko et al. (2018) mapped cropping intensity of rice in Vietnam using Sentinel-1 radar data with $10 \times 10$ and $20 \times 20 \mathrm{~m}^{2}$ resolution and a random forest algorithm. The authors obtained an accuracy of $93.5 \%$ for data with $10 \times 10 \mathrm{~m}^{2}$ resolution.

Other attempts to map cropping intensity were carried out at national scale in India and China. Biradar and Xiao (2011) mapped cropping intensity across India, and Yan et al. (2014) mapped cropping intensity across China, both using again MODIS time series data. Gray et al. (2014) estimated the cropping intensity across all of Asia and found significant difficulties in detecting more than two cropping cycles per year due to missing data (cloud cover). Rufin et al. (2018) examined the effect of reservoir-based irrigation from dams on annual crop succession at the global scale. The authors defined crop succession as the number of years in which arable land was cultivated (against fallowing) for 2001-2012. Data on annual crop succession were derived from MODIS land-cover maps with $500 \times 500 \mathrm{~m}^{2}$ spatial resolution. The authors found that crop succession in irrigation dam command areas was on average $16 \%$ higher compared with rainfed control areas.

While MODIS data might be suitable to identify large spatiotemporal scale changes in cropping patterns, satellite data with higher spatial resolution (e.g., Sentinel-2 and Planet) are likely to deliver more precise estimates, particularly in developing countries that are often comprised of smallholder farming systems, and are more suitable for localized adoption studies. Notably across multiple studies, the accuracy in mapping cropping intensity decreased as cropping practices and crop types became more diverse across the landscape and as plot sizes decreased (e.g., Jain et al. 2017a). Overall, most studies focused on the level or spatial variation of cropping intensities rather than interpreting the results in the context of socioeconomic and ecological conditions with exception of Wilken et al. (2017) and Kastens et al. (2017). Wilken et al. (2017) provided evidence from India that an increasing cropping intensity is associated with decreasing pressure on forest land, which they related to reduced profitability of fuel wood harvesting compared with other job opportunities. Kastens et al. (2017) presented descriptive evidence from Brazil that increasing cropping intensity of soy reduced pressure on forest land. Nevertheless, these papers could not establish causality between the variables of interest and rely rather on descriptive comparisons. In sum, the determinants and effects of the observed intensification processes were left largely unexamined in the current literature.
In connection to increasing cropping intensity, intercropping has been promoted to increase soil fertility, system productivity, and dietary diversity (Brooker et al. 2015). Satellites could potentially identify intercropping through distinguishing crops based on their spectral characteristics as it is already carried out successfully using unmanned aerial vehicles (Yonah et al. 2018). To differentiate intercropping practiced in small plots, information on local intercropping practices as well as plot boundaries are essential. We could not identify any studies that examined intercropping of annual crops with satellite data in developing countries. The spatial resolution of most satellite sensors is not sufficient to identify different crop types within the small plots found in developing countries.

\subsection{Tillage and crop residue cover}

Tillage practices are important determinants of soil quality, input use, land productivity, and cost of production (Krishna and Veettil 2014). Conventionally, farmers use intensive tillage to prepare fine seed beds, with the aim of ensuring uniform germination under weed free conditions. However, intensive tillage tends to reduce soil organic matter, soil carbon, and, under certain circumstances, soil moisture. Conventional tillage is also associated with significant fuel use and cost of cultivation. Against this backdrop, zero tillage or reduced tillage is promoted as a critical component of conservation agriculture. The three major components of conservation agriculture are minimum soil disturbance (zero or reduced tillage), permanent soil cover with crop residues or cover crops, and diversifying production system through crop rotation or intercropping (Hobbs et al. 2008). While the extent of zero tillage is fairly well-documented in high-income countries such as the USA and various incentive schemes are in place to foster farmer adoption (Wallander et al. 2018), the extent to which these practices are adopted in lower income countries is less understood.

So far, only a few studies directly addressed farmer adoption of zero or reduced tillage through remote sensing in developing countries. Two studies used backscattering coefficients, which are derived from radar data. Unlike passive multi-spectral sensors that do not emit radiation themselves, radar systems send electromagnetic pulses with high power and record the backscattered signal. Radar data are hence less affected by weather conditions such as clouds and sunlight. The data contain information about soil surface, physical structure of crop residue, and dielectric properties of the surface, which depend partly on moisture content (Zheng et al. 2014). To relate backscattering coefficients with tillage, a wide variety of variables including moisture or incidence angle have to be taken into account. Moreover, radar data have a low signal-to-noise ratio, making their application to small plots challenging. Hadria et al. (2009) combined multispectral FORMOSAT-2 images and radar images from Envisat to 
produce a high spatial and temporal resolution product to map tillage practices in Morocco for the 2005/2006 agricultural season. Bhargava et al. (2017) estimated the up-take of zero tillage practices in the Gangetic Plains of India. To estimate adoption, the authors used data from a household survey and from Sentinel-1 (radar data) and Sentinel-2. The results showed that $18 \%$ of the cropland area was under zero tillage. The average zero-till mapping accuracy varied between 78 and $90 \%$ for different regions. However, estimates of zero tillage adoption based on satellite data were not in line with census and household data from the same regions. The authors concluded that one of the major reasons for this discrepancy was spatial heterogeneity. The agro-environmental conditions and farming practices were varying drastically across regions, necessitating further ground-truthing. Another caveat was that the individual plot-level adoption of zero tillage was possibly not identified for small parcels, which are commonly found in the eastern Indo-Gangetic Plains. The satellite mapping algorithm did only capture larger land segments with similar spectral characteristics.

Most other studies used multispectral sensors to map tillage indirectly through measuring crop residue cover. Mulching with crop residues is one of the key components of conservation agriculture (Hobbs et al. 2008). The presence of crop residue cover is hence interpreted as direct evidence for reduced or zero tillage. Unlike estimation of zero tillage adoption, self-reported data on the extent of crop residue cover is likely to be imprecise and is often either reported as a simple binary variable or as categorical variable with broad intervals of the extent of crop residue cover (Kosmowski et al. 2017).

Crop residues, live plants, water, and soils have a different spectral signature, which is defined as the variation of reflectance of a material with respect to wavelengths (Tso and Mather 2009). For example, while live plants absorb blue and red light, they emit part of the visible green and in particular infrared (with a wavelength roughly between $700 \mathrm{~nm}$ and $1 \mathrm{~mm}$ ). On the other side, crop residues have a unique absorption feature near $2100 \mathrm{~nm}$, making remote sensing of crop residue cover possible with multi- and hyperspectral-sensors. While multispectral imagery consists usually of three to ten wider bands, hyperspectral imagery consists of more than dozens of bands. Estimation of crop residue cover and tillage requires high temporal resolution satellite data, and these data have to be available during the time of land preparation. Heterogeneous planting dates and crop growth can complicate identification of residue retention (Zheng et al. 2014). In addition, accurate identification is complicated by different decomposition rates and other management practices that affect spectral differences between crop residue and soil. A number of studies tested different indices and estimation methods mostly in high income countries, particularly in the USA (Beeson et al. 2016; Zheng et al. 2014). The most common indices based on the unique absorption feature of crop residue cover include the Cellulose Absorption Index (CAI) and the Normalized Difference Tillage Index (NDTI). The CAI is calculated as $100 *(0.5 *(\mathrm{R} 2.0+\mathrm{R} 2.2)-\mathrm{R} 2.1)$ where $\mathrm{R} 2.0, \mathrm{R} 2.1$, and R2.2 correspond to reflectance values in narrow $10-\mathrm{nm}$ bands centered at 2030,2100, and $2210 \mathrm{~nm}$, which necessitates data from hyperspectral sensors. The NDTI, however, can be calculated from multispectral sensors such as Landsat 8 OLI Band 6 (1566-1651 nm) and Band 7 (2107-2294 nm) as (OLI6 - OLI7)/(OLI6 + OLI7) (Quemada and Daughtry 2016). The NDTI can be obtained from typical multispectral data like Landsat, MODIS, or Sentinel-2. Some studies reported correlation coefficients up to 0.90 for crop residue cover, denoting that accurate estimations are indeed possible (Zheng et al. 2012). A recent study criticized that the high correlation coefficient and $\mathrm{R}^{2}$ values might also be driven by spatial autocorrelation (Azzari et al. 2019).

In developing country context, Wang et al. (2017) tested the potential of SPOT-5 imagery to estimate crop residue cover on the Yellow River Plain in China. The authors showed that SPOT-5 imagery can be used to detect crop residue cover and also stated that Sentinel-2 imagery would be a suitable replacement due to its wide swath, high temporal resolution, and higher number of bands. Kosmowski et al. (2017) compared different methods of crop residue coverage measurement, including satellite imagery and household surveys. Survey data were collected from 197 households and 314 plots in Ethiopia. Landsat 8 TM imagery was used to construct the NDTI. The results showed that all survey-based methods underestimated crop residue cover. The estimates based on satellite imagery, which only need plot boundaries but no additional ground data to construct the NDTI, were more accurate in comparison with self-reported estimates. The accuracy of these estimates was also higher than that of imagery from drones. The authors emphasized that taking into consideration that Landsat has a relatively coarse spatial resolution compared with the small size of plots in the study area $\left(2139 \mathrm{~m}^{2}\right)$ and that the NDTI index was not calibrated, the remote sensing based estimates performed fairly well. Based on evidence from the USA, new and improved indices such as adjusting the NDTI or Shortwave Infrared Normalized Difference Residue Index (SINDRI) for variable moisture conditions are likely to improve prediction accuracies further (Quemada et al. 2018). Azzari et al. (2019) showed that, for detecting tillage practices in the USA from 2005 to 2016, Landsat data performed consistently better than Sentinel-1 radar data with best average accuracy of $79 \%$ for fields and $75 \%$ for states. Also, for the USA, Wallander et al. (2018) showed how the long temporal record of satellite data can be used to evaluate the long-term persistence of technology adoption. Wallander et al. (2018) examined whether the temporary monetary incentives to implement zero tillage resulted in persistent behavioral changes in the USA from 2007 to 2016. After modeling adoption based on field survey data, the 
authors estimated crop residue cover, which served as a proxy for zero tillage, before, during, and after the subsidy implementation. The study analyzed Landsat 5,7 , and 8 data to calculate the NDTI, which was merged with spatially and temporally explicit data on subsidies. The results showed a high level of technology persistence in farmers' fields, even beyond the completion of the subsidy program. There is high potential for similar studies on farmer adoption of new agricultural practices, although these studies necessitate georeferencing of plots with and without interventions.

One of the major advantages of adopting zero tillage is that late sowing, which would result in significant crop loss (especially in case of wheat), can be avoided (Krishna and Veettil 2014). Taking this aspect into consideration, Lobell et al. (2013) measured the trend in sowing dates throughout IndoGangetic Plains and provided an indirect measure of zero tillage adoption between 2000 and 2010. The authors used MODIS and SPOT satellite data. Comparing the estimates with survey data confirmed the capability of satellites to identify sowing dates. Using satellite imagery with low spatial resolution, Chakraborty et al. (2018) mapped cropping seasons and early sowing of wheat in Northern India. The authors used the NDVI from AVHRR data, covering a long time period (from 1981 to 2016). This study forms a typical example of effectively using low resolution data to track long-run trends. The authors showed that, while, in most regions, length of the cropping season was increasing due to early sowing, the length of the cropping season reduced in some other regions.

\subsection{Irrigation}

Approximately $40 \%$ of the world's food production originates from irrigated lands (Thenkabail et al. 2009). While water availability is a major determinant of crop productivity, wasteful application of irrigation often poses a threat to environmental sustainability by depleting and degrading the water resources and by increasing salinity and alkalinity in the soil. Estimating and understanding dynamics of the temporal and spatial expansion of irrigation is therefore an important piece of information to derive production possibilities, regulate water demand, and derive environmentally friendly policies and programs.

Various studies have estimated the extent of irrigation systems using satellite data at local, national, and global scales. At a local scale, Hadria et al. (2009) combined multispectral FORMOSAT-2 images with radar images from Envisat to map irrigation practices in Morocco for the 2005/2006 agricultural season. Biggs et al. (2007) and Thenkabail et al. (2005) used MODIS data to identify different types of irrigation based on source of water (e.g., canal irrigation, groundwater, etc.), using differences in the Normalized Difference Vegetation Indices (NDVI) time signatures in India.
Dheeravath et al. (2010) mapped irrigated areas in India at national and subnational levels based on MODIS data from 2001 to 2003 and found significant differences between census data and remote sensing estimates. While no final verdict on data quality can be provided, the authors suspect measurement errors in the census due to suboptimal accounting of minor irrigation, state agencies withholding data, no comprehensive statistical analyses of data, and subjective biases in data collection. However, remote sensing data might also be prone to measurement error due to sub-pixel area computations, low resolution of the imagery and other methodological issues. Toomanian et al. (2010) mapped irrigation area in the Zayandeh Rud Basin of Iran using NOAA-AVHRR and Landsat 7 ETM+ data. Kamthonkiat et al. (2007) produced maps for irrigated and rainfed rice systems in Thailand using SPOT-4 data, while Gumma et al. (2011) mapped irrigated areas in Ghana using temporal variation in NDVI levels based on Landsat 7 ETM+ and MODIS data. The authors reported a fuzzy classification accuracy between 67 and $93 \%$ for different types of irrigation systems. While they reach only $67 \%$ accuracy for fragmented and minor scale irrigation, they reach 93\% for surface irrigation systems. The authors stress that dug-wells, small ponds, and other fragmented irrigated areas are better captured using very high-resolution data and that accuracy is depending largely on the type of local irrigation systems.

The International Water Management Institute (IWMI) initiated a Global Irrigated Area Mapping (GIAM) project to map the spatial distribution of irrigation areas using various data sources, which include the AVHRR NDVI, SPOT VGT NDVI, JERS-1 SAR data, and University of Maryland Global Tree Cover data. The results are reported by Thenkabail et al. (2009). With ground-truthing of data, the authors reached an accuracy of $79 \%$ to distinguish irrigated areas from nonirrigated ones. The maps do not consider irrigation intensity or seasonality, and, furthermore, the coarse spatial resolution $\left(10 \times 10 \mathrm{~m}^{2}\right)$ resulted in a failure to notice fragmented irrigation systems. A considerable body of literature exists that proxies the water quantities needed for irrigation by estimating the amount of water expelled through evapotranspiration (Arjunan and Nanthakumaran 2016; Jensen and Allen 2016). These studies investigate differences in evapotranspiration between different irrigations systems as well as spatial and temporal variability using satellite imagery. These studies were not included in the present review since they neither focus on technology adoption nor directly estimate yield and economic impacts.

\subsection{Soil and water conservation}

Soil and water conservation (SWC) is a generic term comprising activities aimed at maintaining or enhancing the productive capacity of land, such as reducing soil erosion, salinity, 
and compaction, conserving water resources, and improving soil fertility. Some of these technologies and practices addressing the aforementioned challenges are terraces, stone bunds, check dams, contour ditches, cover crops, and reforestation. A number of socioeconomic studies addressed farmer adoption and impacts of SWC practices, such as Mutenje et al. (2016) and Kamau et al. (2014). Despite having potential, satellite data are yet to become popular as a source of information for mapping SWC practices.

One of the few studies that used satellite data to study adoption of SWC practices (grass strips and bench terraces) is Wickama et al. (2015), which addressed the effectiveness of these practices in slowing down soil erosion in farmers' fields in Tanzania. The study used ASTER (Terra satellite) and WorldView-2 datasets and an object-based image analysis for identification. Accuracy in identifying SWC practices was at $77 \%$ (SWC vs. no-SWC). In a similar study on Eritrea, Eckert et al. (2017) assessed the extent of existing SWC structures focusing on terraces and bunds. Prior to this, no reliable information was available on number and distribution of these structures in Eritrea. The authors used GeoEye-1 satellite data with $0.5 \times 0.5 \mathrm{~m}^{2}$ resolution and an object-based classification approach. They identified the majority of terraces and bunds $(78.5 \%)$ as well as hillside terraces $(81.25 \%)$. We did not review the literature on ground water depletion since measurements are too coarse to be used in the adoption-impact studies (Frappart and Ramillien 2018).

\subsection{Identifying crop types}

A decisive advantage of using satellite imagery in adoption and impact studies is the ability to monitor cultivation of different crops over both time and space. While there is a fair amount of land-use maps using coarse classification classes (for example, crop versus non-crop land), the identification of individual crop types has proved to be a complex procedure. Some reviews on crop type mapping already exists, but they do not include newer developments and are more technical in nature (Delincé 2017; Gómez et al. 2016). Some key studies and newer developments are reported below.

Early attempts of crop type mapping yielded only low prediction accuracies (Fang et al. 1998), a limitation that was overcome with recent estimation methods and data. Kussul et al. (2017) classified crop types in Ukraine using Landsat8 multispectral data and Sentinel-1A radar data. Classification was done applying machine learning algorithms to multitemporal and multisource satellite imagery. The authors reached accuracies of more than $85 \%$ for all major crops including wheat, maize, sunflower, soybeans, and sugar beet. For a single crop type (paddy-rice in China), Zhang et al. (2018) employed a convolutional Neural Network method based on multitemporal Landsat 8 data. Overall accuracy was high at $97 \%$. The literature mapping rice areas in Asia is fairly large (Singha et al. 2016; Son et al. 2014; Wang et al. 2015). Other crops types were also already successfully mapped including soybean, maize, and cotton in Brazil (Arvor et al. 2011), fruit-tree crops in Chile (Peña and Brenning 2015), wheat, barley, alfalfa, and fruit trees in Iran (Asgarian et al. 2016), wheat in Lebanon (Nasrallah et al. 2018), and tree crops in Myanmar (Alban et al. 2018). The study of Lebourgeois et al. (2017) mapped a complete set of crop types in smallholder agricultural areas in Madagascar but accuracy varied greatly for different crop types. A few more global exercises also exist. Inglada et al. (2015) and Defourny et al. (2019) mapped crop types in various study areas across the globe using high spatial resolution time series such as Sentinel-2. Inglada et al. (2015) found that their approach yielded overall accuracies above $80 \%$ for most sites. However, in African agricultural systems, they attained low accuracies in Madagascar due to the presence of small fields and in Burkina Faso due to the intercropping of trees and annual crops. Defourny et al. (2019) demonstrated the performance of the Sentinel-2 for Agriculture (Sen2-Agri) system in eight local sites and three countries (Ukraine, Mali, and South Africa) including a wide range of crops, landscapes, and agricultural practices. The Sen2-Agri project was launched by the European Space Agency to provide data products relevant for crop monitoring such crop type maps. The authors stressed that accuracy depends on crop calendars as some crops are more accurately mapped during certain growth stages and that, as for other research, small fields and intercropping are a major problem for identification.

Besides studies in low- and middle-income countries, multiple attempts of crop classification were undertaken in highincome countries (e.g., Immitzer et al. 2016; Inglada et al. 2016). The prediction accuracies are likely to increase in the future due to the increasing availability of multisource and multitemporal satellite imagery as well as improved machine learning algorithms (Ji et al. 2018; Zhu et al. 2017). Also, the availability of satellite imagery with higher spatial resolution is likely to increase the number of applications in the context of the highly fragmented and heterogeneous agricultural landscapes typically found in developing countries. Besides identifying different crop types, an emerging literature on identifying different crop varieties exists, which so far has focused mostly on sugarcane and vineyard crops (Bégué et al. 2018).

\section{Measuring crop yield and yield effects}

In this section, we focus on how satellite data can help estimate the yield impacts of agricultural practices at the field level. While farmers are able to report adoption of technologies, for instance zero tillage, they often fail to state the crop output and plot sizes precisely (Lobell et al. 2018). This could lead to large measurement errors and biased impact 
assessments. Studies using satellite data have significant potential to correct these errors and biases. Most of the studies that use satellite data for yield estimation are built on the fact that vegetation indices are linked to the biomass of the vegetation on the ground. However, approaches for translating these vegetation indices into agricultural yields vary significantly in their estimation methods, crop type, the amount of ground data needed for calibration of models, and precision.

\subsection{Measuring crop yield}

One of the notable studies on estimating yields using satellite data is Lobell et al. (2018), which employed Sentinel-2A imagery to estimate plot-level maize yields in Uganda. The authors compared the accuracy of satellite yield estimates derived using sub-plot crop cutting, full-plot crop cutting, and crop model simulations (which require no ground data, see Scalable Crop Yield Mapper method or SCYM developed in Lobell et al. (2015)) for calibration. Yield models were developed by regressing the MTCI (MERIS Terrestrial Chlorophyll Index) on crop cutting or crop model simulation data. The obtained regression coefficients were used to estimate yields for plots with no crop cutting data. The authors found that, while self-reported yields had almost no correlation with full-plot crop cutting, remotely-sensed yields explained half of full-plot crop cutting yield variability on pure stand plots above 0.1 ha. Satellite yield estimates calibrated using only crop model simulations were able to capture the overall variation in yield as well as crop cut trained models, however, overestimated yields.

Burke and Lobell (2017) estimated smallholder maize yield in western Kenya, using SkySat imagery with $1 \times 1 \mathrm{~m}^{2}$ resolution and extensive ground-based survey data. The study found high correlations between estimates based on satellite and survey data. The results further showed that it is possible to estimate the effects of fertilizer and seed types using yield estimates based on satellite data. Their results suggested that higher resolutions of $1 \times 1 \mathrm{~m}^{2}$ to $5 \times 5 \mathrm{~m}^{2}$ significantly improve accuracy (up to $\mathrm{R}^{2}$ of 0.4 ) compared with $10 \times 10 \mathrm{~m}^{2}$ (Sentinel) or $30 \times 30 \mathrm{~m}^{2}$ (Landsat), which yield $\mathrm{R}^{2}$ ranging from 0.1 to 0.3 . Jin et al. (2017) expanded the estimation approach using data across larger scales and testing different indices and data, confirming that fairly accurate yield estimates can be obtained using satellite imagery. Using SkySat imagery Jain et al. (2016) estimated wheat yield of smallholder farms in Bihar, India. They evaluated the performance of crop models to simulate the necessary ground-truth data to train their remote sensing algorithms. For yields, crop cut parameterized models had the highest accuracies with $\mathrm{R}^{2}$ value of 0.3. Yields calibrated using self-reported data performed considerably worse with $\mathrm{R}^{2}$ value of 0.1 , while yields calibrated using crop model data obtained $\mathrm{R}^{2}$ ranging from 0.2 to 0.3 . Although the $\mathrm{R}^{2}$ value was relatively low, crop model parameterized yield estimates from SCYM are produced with significantly less cost and time compared with crop cut parameterized yields. In another study, Jain et al. (2017b), following a similar approach, transformed satellite vegetation indices into yield estimates using data from crop models for parameterization. Simulated yields as well as simulated Green Chlorophyll Vegetation Index (GCVI) were obtained from the SCYM method (Lobell et al. 2015). They applied a linear regression to relate simulated yields and the GCVI. As the last step, the regression coefficients were derived from the linear model on actual Landsat GCVI and MODIS minimum temperatures in order to calculate mean yields over the time period 2001-2015. At the district level, the authors obtained correlation coefficients ranging from 0.5 to 0.8 when comparing satellite-based yield estimates to district-level census data (correlation coefficients are higher compared with other cited studies due to the high aggregation level).

Other studies concerned with measuring crop yields in developing countries include Lambert et al. (2018), who estimated smallholder yields in Mali using Sentinel-2 data, and Schulthess et al. (2013), who used $5 \times 5 \mathrm{~m}^{2}$ RapidEye data to estimate maize yield and yield gaps at the field scale in Bangladesh. Zhao et al. (2017) estimated rice yields in China using FORMOSAT-2 data. In developed country agriculture, a number of studies have accurately estimated yields. He et al. (2018) combined MODIS and Landsat datasets to derive gross primary productivity and interacted this variable with empirical harvest indices to derive yields of a number of crops, including wheat, in the USA. Khanal et al. (2018) combined machine learning and satellite data to predict maize yields in the USA. Lobell and Azzari (2017) estimated maize yield heterogeneity in the USA. Several other studies estimated yields of staple crops such as maize and wheat at the district or country level (Becker-Reshef et al. 2010; Funk and Budde 2009; Labus et al. 2010). Besides measuring crop yield, remote sensing data are also increasingly used for seasonal crop yield forecast. While crop yield estimation is done after harvesting is completed, crop yield forecast is done within the season prior to harvesting, which makes such data in particular relevant for predicting food shortages (Basso and Liu 2019).

\subsection{Measuring yield effects}

The studies cited in Section 4.1 clearly show that a significant literature exists on the use of satellite data to estimate crop yields and yield gaps. On the other hand, only a limited number of these studies assess yield effects of technological interventions in developing countries. There exist some notable studies on the yield effects of dams at the national and crosscountry level. Strobl and Strobl (2011) examined the impact of large dams on agricultural productivity in Africa. They mapped cropland area based on the Global Land Cover 2000 dataset (SPOT-4 imagery) and then estimated the net primary production (NPP) over time based on MODIS data. The 
MODIS NPP data products are directly available from various data platforms at a $1 \times 1 \mathrm{~km}^{2}$ resolution at an annual basis. With a spatial resolution at $1 \times 1 \mathrm{~km}^{2}$, it is likely that spatially segregated smaller farms were not captured in the estimation. Blanc and Strobl (2014) investigated the effect of small versus large dams on agricultural productivity in South Africa. To estimate agricultural productivity, they followed the same approach as Strobl and Strobl (2011).

A few papers investigated the yield effects of crop succession with satellite data. Yamamoto et al. (2009) estimated the effect of crop-fallow rotation cycles on agricultural production in Laos. They used brightness and greenness indices to distinguish between land with vegetation cover and bare land between 1996 and 2003. The study has achieved an accuracy of only $69 \%$ in identifying the duration of fallow. To assess the impact of fallow duration on crop productivity, the authors used the NDVI as a coarse proxy for productivity. Another set of papers studied the yield effect of sowing dates, which is one of the important yield-determining factors for seasonal crops such as wheat. Ortiz-Monasterio and Lobell (2007) assessed the yield impact of sowing dates and weed infestation during the fallow period on wheat yields in the Yaqui Valley, Mexico. The authors used Landsat-7 ETM+ images to estimate wheat yield and sowing dates, using a more detailed approach to estimate crop yield compared with the previous listed studies. The estimation was based on yield as a function of the total amount of Photosynthetically Active Radiation (PAR) absorbed by the canopy throughout the growing season, light-use efficiency, and the ratio of grain mass to aboveground biomass. The authors used data from experimental plots to measure the latter two variables. To estimate PAR absorbed by the canopy, the authors employed satellite imagery. Weed infestation during fallow was differentiated from other land uses based on the NDVI values. The estimation procedure was described in detail by Lobell et al. (2003).

Bellora et al. (2017) used the NDVI derived from SPOT-5 satellite imagery, combined with land use classification to quantify crop biomass to study the effect of crop diversity on resilience and productivity. The authors used field boundaries and land use classification to compute an index on crop diversity. Increase in surrounding biodiversity was found to improve crop survival ratios and crop productivity.

This review shows that the literature using satellite data to estimate the impact of agricultural practices on yield, despite having great potential, is still limited. Most current applications that estimated the impact of certain interventions on yields only used crop biomass or the NDVI or NPP as a yield proxy. Small-scale agricultural production systems with high crop diversity in developing countries posed a substantial problem for past yield estimates based on satellite data. More recent studies showed that fairly precise yield estimates can be obtained using high-resolution satellite imagery. Moreover, even though the correlation coefficient or explanatory power remained often rather low, several studies showed that the estimates still contain meaningful variation. For example, Lobell et al. (2018) showed that their yield estimates allow for accurate estimates on the effects of soil quality and fertilizer application. Jain et al. (2016) showed that their yield estimates $\left(R^{2}=0.33\right)$ picked up the effect of sow date on yield. Yet, the current approaches possess certain limitations. First, although many authors have indicated that crop model data might suffice to calibrate yields, precise ground-truthing, such as crop cutting data, is required to increase accuracy. This would require substantial human and financial resources. Second, most models assume a uniform relationship between vegetation indices and yields within a certain cropping system. However, these relationships are unlikely to be stable. They could be a function of crop varieties used, the agroecological conditions, and management methods. Researchers hence need to consider the homogeneity of the study region. Any extension of one particular yield estimation method to another region and/or year has to be carried out with caution.

\section{Measuring environmental and economic outcomes}

\subsection{Measuring environmental outcomes}

In this subsection, we review studies that captured the environmental effects of agricultural practices with satellite data. There are not many studies in this genre, and the existing ones addressed mainly the effects of (a) crop residue burning on air quality and (b) adoption of SWC practices on biophysical properties such as NDVI.

Burning is often the cheapest and quickest way to dispose crop residues to allow land preparation for the next crop. However, this practice is shown to adversely affect various ecosystem services as well as human health (Lelieveld et al. 2015). Liu et al. (2018b) examined the effects of outdoor biomass burning on air quality in India. The authors identified fire activity using MODIS data and combined their results with atmospheric trajectory modeling as well as ground and satellite-based air quality observations. The MODIS active fire products (Collection 6) use brightness temperature, measuring the radiance of the microwave radiation to map active fires. Several additional steps, such as using information of surrounding pixels and masking out certain land uses, are required to reach an accurate estimation (Giglio et al. 2016). Most papers relate the observed fires from the MODIS active fire products to the burning of crop residues by incorporating timing and location of the fires. Vijayakumar et al. (2016) examined the impact of crop residue burning on air quality indicators focusing on northern India. Their analysis was built on MODIS data, which was complemented with data from the 
Ozone Monitoring Instrument (Aura) and the CALIPSO satellite platform. Kaskaoutis et al. (2014) reiterated the farreaching effects of rice residue burning in northern India. In the near future, Visible Infrared Imaging Radiometer Suite (VIIRS) active fire data, the spatial resolution of which has increased from $1 \times 1 \mathrm{~km}^{2}$ to $375 \times 375 \mathrm{~m}^{2}$, are likely to improve fire-detection accuracy in comparison with the MODIS data (Product Title: VIIRS I Band 375 m Active Fire Product NRT). Lasko et al. (2018) studied the effect of rice residue burning, focusing particularly on different burning practices, such as pile burning (mostly applied in hand-harvested fields) and non-piled burning (used in machine-harvested fields). The authors estimated harvest dates based on the date of maximum backscatter derived from Sentinel-1 data, and they estimated the burn date by adding 3 days to the date of maximum backscatter. Estimates on the emissions originating from different farm management practices were obtained from the literature.

Another approach to delineate areas with residue burning is through estimating vegetation indices. However, only a few studies have estimated burned areas within agricultural landscapes following this approach. Wang et al. (2018) identified winter wheat and burned area spectral signatures through field experiments in central China. The study employed Vegetation Difference Index (VDI) and Burn Scar Index (BSI) models to estimate the burned crop area.

The second set of environmental impact studies is in relation to the SWC practices. We found two studies in this connection. From 2009 to 2015, Ethiopia's Tana Beles Integrated Water Resource Development Project supported SWC and tree planting in micro-watersheds. To estimate the project's impact, Ali et al. (2018) applied Landsat-7 ETM+ imagery to compute NDVI and Soil Adjusted Vegetation Index (SAVI) to measure vegetation cover before and after the project implementation. They also computed Land Surface Water Index (LSWI) as a measure of plant and soil water content. Five-kilometer buffers around the treated watersheds served as the control regions. The authors applied a difference-indifference approach with pixel-level fixed effects to study the environmental impacts. The results indicated significant positive effects of SWC practices on soil water content and photosynthetic activity and that impact magnitudes were increasing over time. In another study, Shanwad et al. (2008) applied satellite data to evaluate an integrated wasteland development program in India for 1997-2001, employing NDVI values to derive the project's effects on reestablishing vegetation.

\subsection{Measuring economic outcomes}

Application of satellite imagery is highly useful for obtaining the indicators of economic activity over a large geographical area for a long period in time, for which secondary datasets are noisy or unavailable. In this section, we discuss how satellite imagery can help estimate poverty and economic activity and thus be potentially useful to evaluate the economic impact of agricultural interventions in rural areas of developing countries. However, the literature is scant; we found only a single study that actually used satellite data to estimate the economic outcome of a specific agricultural technology. Biffis and Chavez (2017) estimated the effect of irrigation on economic returns, using the example of smallholder maize farmers in Mozambique. Data were obtained from NASA MERRA open source data set, which was built on information from various satellite systems, and using numerical models to produce temporally and spatially consistent estimates of climate variables. The authors analyzed this dataset and estimated pixel-level optimal excess heat, deficit precipitation indices, and synthetic crop yields. The authors used the magnitude of reduction in crop insurance costs to quantify the economic gains from irrigation. The changes in crop insurance cost were estimated based on a modeling approach. Risk profiles were computed based on the distributions of production losses determined by pixel-level optimal weather indices. Risk profiles changed from rainfed maize to irrigated maize production due to mitigating soil moisture deficit stress. The cost of irrigation infrastructure was calculated using the FAOSTAT infrastructure cost database. The authors calculated that at least $30 \%$ reduction in insurance costs is possible through providing irrigation in the region.

The potential to use satellite data to estimate the economic effects of agricultural interventions is huge, but remains untapped. One of the most commonly used datasets to identify and estimate economic activity is the night-time lights (NTL) data from the Defense Meteorological Satellite Program (DMSP). The Earth Observation Group (EOG) at the National Oceanic and Atmospheric Administration (NOAA) has been archiving and processing the DMSP's NTL data since 1994 at a resolution of approximately $1 \times 1 \mathrm{~km}^{2}$. In 2014, Huang et al. (2014) found 189 different journal articles that used DMSP data. However, several researchers questioned the suitability of NTL data for economic research due to low resolution, "light spillovers" to neighboring pixels, and, lastly, underestimation of economic activities in rural areas, such as agriculture, that emit a little or no light at night (Bundervoet et al. 2015; Keola et al. 2015).

While previous NTL data do not seem promising for impact evaluation, new sensors may potentially help researchers quantify NTL at finer spatial resolutions. In 2011, the Suomi National Polar Partnership satellite was launched carrying a VIIRS instrument. Studies showed that VIIRS, with resolutions ranging from 375 to $750 \mathrm{~m}^{2}$ (at nadir, depending on the sensors), performs substantially better than the DMSP-OLS. Also the VIIRS is sensitive to very low levels of visible light, which might be necessary to capture the economic activity in rural areas (Chen and Nordhaus 2015; Hillger et al. 2013; Wu 
et al. 2018). Finally, NASA's Black Marble night-time lights product suite (VNP46) started to provide high-quality, cloudfree, atmospheric-, terrain-, vegetation-, snow-, lunar-, and stray light-corrected radiances in 2018. This would facilitate estimation of NTL based on VIIRS data, following the successful work of the EOG team and their DMSP dataset (Román et al. 2018). While the resolution is still far too coarse to estimate economic activity at the farm-household level, these developments may facilitate a better prediction of regional trajectories. For example, if agricultural development interventions target specific villages or larger entities, it could be of interest to track the interventions' impacts on economic activity over time through changes in night-time lights.

Besides NTL data, other approaches are being used to proxy economic activity. Although these approaches are not yet applied to measure the impact of agricultural interventions, they illustrate the potential of deriving economic variables from satellite data to track longer term economic outcomes. For instance, Engstrom et al. (2017) mapped infrastructure in Sri Lanka, including the number and density of buildings, prevalence of shadows (proxy for building height), number of cars, density and length of roads, type of farmland, and roof material, employing daytime imagery from WorldView-2, GeoEye-1, and QuickBird-2, as well as machine learning algorithms. The authors showed that, in linear regression models, the extracted features could explain about $60 \%$ of census-based poverty headcount rates and average household consumption. In particular, building density, built-up area, number of buildings, shadow pixels, and, to some extent, vegetation explained up to $45 \%$ of the variation in poverty. In comparison, models using NTL explained only up to $15 \%$ of the variation in the poverty indicators. Babenko et al. (2017) employed convolutional neural networks to estimate poverty rates in Mexico using Planet and Digital Globe imagery with spatial resolutions of $3 \times 3 \mathrm{~m}^{2}$ to $5 \times 5 \mathrm{~m}^{2}$ and $0.5 \times 0.5 \mathrm{~m}^{2}$ respectively. The convolutional neural networks, trained using poverty data from 896 municipalities, yielded a correlation coefficient of about 0.60 for poverty rates in the validation sample. The explanatory power, however, was drastically reduced when applied outside the validation sample.

Jean et al. (2016) analyzed both day- and night-time satellite data as well as survey data from Nigeria, Tanzania, Uganda, Malawi, and Rwanda and indicated that convolutional neural networks can explain up to $75 \%$ of the variation in economic outcomes, such as household consumption and asset status. Head et al. (2017) replicated this approach in Rwanda, Nigeria, Haiti, and Nepal and were able to estimate asset status with relatively high accuracy $\left(\mathrm{R}^{2}\right.$ $0.50-0.70$ ), however, only by considerably fine-tuning the Jean et al. (2016) code.

The aforementioned approaches have only estimated the average asset status across different regions. However, asset status does not necessarily correlate with other key developmental indicators such as education and weekly consumption expenditure and is rather a long-term outcome of households' economic activity that might only slowly change due to the immediate variations in households' economic status. This bears three important lessons for the applications of such data in agricultural impact studies. First, while many agricultural interventions demonstrate an immediate yield effect, the economic effects may appear only gradually over time, making satellite data less useful in capturing these impacts. Second, since satellite data will be aggregated at a higher spatial level, it is more useful to study the impacts at the meso-level rather than at the micro-level. Lastly, since these data do not strongly correlate with some welfare indicators such as health and education, it will be still indispensable to acquire complementary field survey data.

\section{Future prospects}

Although the scope of applications of satellite data to assess adoption and impacts of agricultural practices is consistently widening, there exists an untapped potential to better integrate satellite data with field surveys. Most countries provide secondary data on socioeconomic characteristics, for example, population density, wealth, and infrastructure, that can be effectively linked with estimates on the expansion of agricultural practices. This could improve our knowledge on the factors driving adoption patterns of agricultural practices. Unlike in the reviewed studies, a considerable body of literature does exist linking land cover and land use changes (like deforestation and agricultural expansion) to socioeconomic variables (Mondal et al. 2016; Richards and Friess 2016).

Some of the important stepping-stones towards this goal include improving estimation and data extraction procedures, increasing accessibility and availability of preprocessed satellite data and facilitating georeferencing of ground-level data. While drawing mere correlations between agricultural practices and various outcome variables is relatively easy, more refined estimation methods are essential to elicit causal effects. Satellite data can augment conventional adoption and impact studies by providing important variables that cannot be captured easily using farm-household surveys. Econometric estimation procedures could be enhanced using remotely sensed control variables, for example, through matching farmers from regions with comparable agro-ecological characteristics and farming practices. Satellite data can also improve difference-in-differences approaches by estimating before and after treatment outcomes and testing the underlying assumptions of parallel trends. By comparing trends over time between a treatment group and a control group, researchers often implicitly assume that any difference in trends is due to the treatment or intervention. However, if the treatment group was on a different growth track even before the intervention, 
for example, having faster yield increases than the control group, one would falsely attribute the faster growth in yield to the treatment. Also, spatial regression discontinuity designs could become more commonly applied with the help of remote sensing (BenYishay et al. 2017). In addition, location fixed effects could be used to control for some of timeinvariant unobserved heterogeneity. A better integration of spatial econometrics with satellite data could also be beneficial. Spatial econometrics allows measuring both direct effects as well as spillover effects through, for example, spatial Durbin models or simpler SLX models (Halleck Vega and Elhorst 2015). Other key applications of satellite data include better identification strategies for causal estimations. Adoption and impact studies often suffer from selection biases since unobserved individual farmer or farm characteristics may influence up-take as well as outcomes. Adoption is also influenced by agro-ecological conditions that are, however, unlikely to correlate with individual characteristics. Such exogenous variation could help construct instrumental variables. Moreover, satellite data can be used during sample selection for meaningful stratification, such as across agro-ecological zones or different levels of soil fertility.

For variable extraction from satellite imagery, machine learning is one of the most promising tools. Due to the large amount of data, it is often difficult to relate satellite data to variables based on simple models. Machine learning can effectively relate raw data to meaningful outcomes in much more complex ways that allow for non-linearity and interactions across variables. Jean et al. (2016) is one of the earliest studies demonstrating how machine learning algorithms can be trained to predict poverty from satellite imagery.

Concerning the availability and accessibility of satellite data, some of the recent developments are noteworthy. The Copernicus program (Sentinel satellites) followed in the footsteps of Landsat making its data open-access while increasing the spatial resolution from $30 \times 30$ to $10 \times 10 \mathrm{~m}^{2}$. The VIIRS data products are also replacing MODIS data to continue on the coarse-resolution, long-term data records, while improving data quality considerably (Skakun et al. 2017). Other initiatives focus on delivering near-real-time or even real-time data to facilitate monitoring and immediate interventions $(\mathrm{Li}$ et al. 2018; Liu et al. 2018a). Also, private companies extend the portfolio of available satellite imagery. Private companies such as Planet or DigitalGlobe operate more satellites than any organization besides the USA and Russian governments, providing coverage of the entire globe with multispectral imagery resolution down to $1 \times 1 \mathrm{~m}^{2}$. Having global and open access products on various key variables is also crucial. For instance, Digital Soil Mapping (DSM) use environmental characteristics derived from satellite imagery to predict soil properties on various scales. Vågen et al. (2016) present models for digital soil mapping based on MODIS data and 114 sites with each 160 sampling plots (10,473 topsoil samples) across Sub-
Saharan Africa. The authors produce maps for soil indicators such as soil organic carbon, $\mathrm{pH}$ and sand, data that can be highly valuable for adoption and impact studies. Besides new satellite programs, open-access policies, and data products, the availability of powerful and cost-free platforms such as Google Earth Engine (GEE) have greatly reduced the costs for image acquisition and processing. These platforms provide access to various types of preprocessed imagery in the cloud as well as algorithms to further process the data. Besides GEE, several platforms have built up databases with tools to easily extract data. These platforms include Aiddata, Copernicus Open Access Hub (Sentinel data), GLCF (Global Land Cover Facility), the Radiant Earth Foundation, and the USGS (United States Geological Survey) Earth Explorer.

Over the last few years, the availability of georeferenced household and plot data has greatly increased, allowing researchers to merge ground-based survey data easily with satellite data. The World Bank provides, for example, a georeferenced dataset, which includes all World Bank projects based on funding from the IBRD (International Bank for Reconstruction and Development) or the IDA (International Development Association) from 1995 to 2014. This dataset includes 5684 geocoded projects across 61,243 locations. Concerning household data, DHS (Demographic and Health Survey) and LSMS (Living Standards Measurement Study) datasets are nowadays georeferenced at the enumeration area level. However, although georeferencing is becoming more and more common, it is still far from universal or uniform across geographies. Furthermore, for surveys that recorded GPS data, it is common to solely georeference locations of interviewed households or enumeration area rather than taking additional data on farm location and plot boundaries, not least to protect privacy concerns. Aside from walking plot boundaries, new approaches for area measurement such as using offline satellite maps for outlining the area on tablets are likely to decrease additional costs. Further efforts in this area can foster the integration of survey and satellite data.

\section{Conclusion}

The present study showed that, while the literature focusing on improving the accuracy of mapping agricultural practices through satellite data is extensive, actual applications of satellite data for adoption and impact studies of agricultural practices in developing countries are still in the infancy stage. Concerning the adoption of agricultural practices, most studies focused on employing different indices, bands, or resolutions in order to improve the accuracy of identifying agricultural practices or only estimated the level of adoption and spatial variation rather than explaining the observed adoption patterns. Satellite imagery has also been rarely used to estimate the yield and welfare impacts of agricultural practices. 
Only a few studies hence effectively exploit the main advantage of satellite data, that the impact evaluations can be implemented remotely, retrospectively, and at low costs, which also allows researchers to measure long-term impacts (Ali et al. 2018; Wallander et al. 2018). Lobell et al. (2018) and Jean et al. (2016) illustrated novel approaches for how potential outcome variables such as yield and economic activity can be estimated with high accuracy through satellite imagery.

While the usage of satellite data is still limited in studies focusing on adoption and impacts of specific agricultural innovations, satellite data are already more commonly used for other applications. Numerous papers showed that satellite data can be used to identify changes in land cover such as deforestation and agricultural expansion as well as to find linkages with socioeconomic variables. In addition, a considerable body of work exists that uses satellites to study the determinants of yield gaps, illustrating the potential benefits of merging different data sources.

Yet, the application of satellite data should not be limited to measuring key variables at the farm level. The data can also be used to contextualize studies and help interpret results. However, since satellite data are unable to detect various key variables in the development context such as education, health, empowerment, labor hours, or wages, it is important to foster integration rather than replacement of conventional approaches, such as collecting household survey data, in adoption-impact studies. Additionally, developmental researchers have to be cautious about the problems that remote sensing harbors, such as measurement errors produced by mixed pixels (Choodarathnakara et al. 2012), unclear indicators for measurement accuracy (Azzari et al. 2019), and high temporal and spatial variation in the performance of indices in identifying different agricultural practices.

We see several explanations for the slow pickup of remote sensing applications for adoption-impact studies in developing countries. First, until recently, most open-access satellite data such as Landsat did not have a sufficient fine resolution to identify the small plots typically found in developing countries. Additionally, many directly available data products derived from MODIS and DMSP have coarse resolutions, which only allow for the evaluation of large-scale projects. Second, while datasets that are preprocessed and easily accessible, such as the DMSP NTL dataset, have been popular among economists, most satellite data are not preprocessed. Preprocessing necessitates substantial technical knowledge and time to produce required outputs. Third, agricultural and economics departments might not be sufficiently connected with remote sensing departments to allow for knowledgeand methodology-spillovers. Most reviewed studies have been more concerned with evaluating the accuracy of identification than interpreting the socioeconomic or ecological meaning of their results. As a result, most papers are technical and published solely in the disciplinary journals of remote sensing. We believe that addressing this gap might improve current approaches in adoption and impact studies. This paper hopes to facilitate and enhance the collaboration between researchers from the fields of remote sensing and economics, illustrating current and potential applications of satellite data for measuring up-take and impacts of agricultural practices.

Acknowledgments We thank Olaf Erenstein, Bruno Gerald, Kai Sonder, and all the participants of the seminar conducted at CIMMYT Head Quarters, Texcoco, Mexico, in December 2018, for their helpful comments. We also thank three anonymous reviewers and the editors of this journal for valuable comments.

Funding information This study received support from the CGIAR Research Program on wheat agri-food systems (CRP WHEAT) in the form of consultation fee of the first author (C Kubitza) and salary of the other two authors (U Schulthess and V Krishna) during 2018.

\section{Compliance with ethical standards}

Disclaimer The funder had no other role in study design, data collection, preparation of the manuscript, and decision to publish. The views expressed here are those of the authors and do not necessarily reflect the views of the funder or associated institutions.

Conflict of interest The authors declare that they have no conflict of interest.

\section{References}

Ali DA, Deininger K, Monchuk D (2018) Using satellite imagery to assess impacts of soil and water conservation measures: evidence from Ethiopia's Tana-Beles watershed. Policy Research Working Paper 8321

Arjunan K, Nanthakumaran A (2016) Identifying an appropriate and sustainable irrigation method using some remotely sensed parameters for the crop cultivation in Vavuniya district. Proc Food Sci 6: 127-132. https://doi.org/10.1016/j.profoo.2016.02.030

Arvor D, Jonathan M, Meirelles MSP, Dubreuil V, Durieux L (2011) Classification of MODIS EVI time series for crop mapping in the state of Mato Grosso, Brazil. Int J Remote Sens 32:7847-7871. https://doi.org/10.1080/01431161.2010.531783

Asgarian A, Soffianian A, Pourmanafi S (2016) Crop type mapping in a highly fragmented and heterogeneous agricultural landscape: a case of Central Iran using multi-temporal Landsat 8 imagery. Comput Electron Agric 127:531-540. https://doi.org/10.1016/j.compag. 2016.07.019

Azzari G, Grassini P, Edreira JIR, Conley S, Mourtzinis S, Lobell DB (2019) Satellite mapping of tillage practices in the North Central US region from 2005 to 2016. Remote Sens Environ 221:417-429. https://doi.org/10.1016/j.rse.2018.11.010

Babenko B, Hersh J, Newhouse D, Ramakrishnan A, Swartz T (2017) Poverty mapping using convolutional neural networks trained on high and medium resolution satellite images, with an application in Mexico. NIPS 2017 Workshop on Machine Learning for the Developing World. https://arxiv.org/pdf/1711.06323. Accessed 2 December 2018

Basso B, Liu L (2019) Seasonal crop yield forecast: methods, applications, and accuracies. Adv Agron 154:201-255. https://doi.org/10. 1016/bs.agron.2018.11.002 
Becker-Reshef I, Vermote E, Lindeman M, Justice C (2010) A generalized regression-based model for forecasting winter wheat yields in Kansas and Ukraine using MODIS data. Remote Sens Environ 114: 1312-1323. https://doi.org/10.1016/j.rse.2010.01.010

Beeson PC, Daughtry CST, Hunt ER, Akhmedov B, Sadeghi AM, Karlen DL, Tomer MD (2016) Multispectral satellite mapping of crop residue cover and tillage intensity in Iowa. J Soil Water Conserv 71: 385-395. https://doi.org/10.2489/jswc.71.5.385

Bégué A, Arvor D, Bellon B, Betbeder J, de Abelleyra D PD, Ferraz R, Lebourgeois V, Lelong C, Simões MR, Verón S (2018) Remote sensing and cropping practices: a review. Remote Sens 10:99. https://doi.org/10.3390/rs10010099

Bellón B, Bégué A, Lo Seen D, Lebourgeois V, Evangelista BA, Simões M, Demonte Ferraz RP (2018) Improved regional-scale Brazilian cropping systems' mapping based on a semi-automatic object-based clustering approach. Int J Appl Earth Obs Geoinf 68:127-138. https://doi.org/10.1016/j.jag.2018.01.019

Bellora C, Blanc É, Bourgeon J-M, Strobl E (2017) Estimating the impact of crop diversity on agricultural productivity in South Africa. NBER Working Paper (23496). Accessed 15 June 2018

BenYishay A, Runfola D, Trichler R, Dolan C, Goodman S, Parks B, Tanner J, Heuser S, Batra G, Anand A (2017) A primer on geospatial impact evaluation methods, tools, and applications. AidData Working Paper 44

Bhargava AK, Boudot C, Butler A, Chomé G, Gupta K, Singh R, Schulthess U (2017) Conservation agriculture: documenting adoption across the Gangetic Plains of India. Final Report. Accessed 27 June 2018

Biffis E, Chavez E (2017) Satellite data and machine learning for weather risk management and food security. Risk Anal 37:1508-1521. https://doi.org/10.1111/risa.12847

Biggs TW, Thenkabail PS, Gumma MK, Scott CA, Parthasaradhi GR, Turral HN (2007) Irrigated area mapping in heterogeneous landscapes with MODIS time series, ground truth and census data, Krishna Basin, India. Int J Remote Sens 27:4245-4266. https:// doi.org/10.1080/01431160600851801

Biradar CM, Xiao X (2011) Quantifying the area and spatial distribution of double- and triple-cropping croplands in India with multitemporal MODIS imagery in 2005. Int J Remote Sens 32:367386. https://doi.org/10.1080/01431160903464179

Blanc É, Strobl E (2014) Is small better?: a comparison of the effect of large and small dams on cropland productivity in South Africa. World Bank Econ Rev 28:545-576. https://doi.org/10.1093/wber/ lht026

Brooker RW, Bennett AE, Cong W-F, Daniell TJ, George TS, Hallett PD, Hawes C, Iannetta PPM, Jones HG, Karley AJ, Li L, McKenzie BM, Pakeman RJ, Paterson E, Schöb C, Shen J, Squire G, Watson CA, Zhang C, Zhang F, Zhang J, White PJ (2015) Improving intercropping: a synthesis of research in agronomy, plant physiology and ecology. New Phytol 206:107-117. https://oi.org/10.1111/nph. 13132

Brown JC, Kastens JH, Coutinho AC, Victoria DC, Bishop CR (2013) Classifying multiyear agricultural land use data from Mato Grosso using time-series MODIS vegetation index data. Remote Sens Environ 130:39-50. https://doi.org/10.1016/j.rse.2012.11.009

Bundervoet T, Maiyo L, Sanghi A (2015) Measuring national and subnational economic growth from outer space in Africa, with an application to Kenya and Rwanda. Policy Research Working Paper (7461). Accessed 18 June 2018

Burke M, Lobell DB (2017) Satellite-based assessment of yield variation and its determinants in smallholder African systems. Proc Natl Acad Sci U S A 114:2189-2194. https://doi.org/10.1073/pnas. 1616919114

Carletto C, Savastano S, Zezza A (2013) Fact or artifact: the impact of measurement errors on the farm size-productivity relationship. J
Dev Econ 103:254-261. https://doi.org/10.1016/j.jdeveco.2013.03. 004

Chen X, Nordhaus WD (2015) A test of the new VIIRS lights data set: population and economic output in Africa. Remote Sens 7:49374947. https://doi.org/10.3390/rs70404937

Chakraborty D, Sehgal VK, Dhakar R, Das DK, Sahoo RN (2018) Trends and change-point in satellite derived phenology parameters in major wheat growing regions of North India during the last three decades. J Indian Soc Remote 46:59-68. https://doi.org/10.1007/s12524-0170684-8

Chivasa W, Mutanga O, Biradar CM (2017) Application of remote sensing in estimating maize grain yield in heterogeneous African agricultural landscapes: a review. Int J Remote Sens 38:6816-6845. https://doi.org/10.1080/01431161.2017.1365390

Choodarathnakara AL, Kumar TA, Koliwad S, Patil CG (2012) Mixed pixels: a challenge in remote sensing data classification for improving performance. Int J Adv Res Comput Eng Technol 1:261-271

Defourny P, Bontemps S, Bellemans N, Cara C, Dedieu G, Guzzonato E, Hagolle O, Inglada J, Nicola L, Rabaute T, Savinaud M, Udroiu C, Valero S, Bégué A, Dejoux J-F, El Harti A, Ezzahar J, Kussul N, Labbassi K, Lebourgeois V, Miao Z, Newby T, Nyamugama A, Salh N, Shelestov A, Simonneaux V, Traore PS, Traore SS, Koetz B (2019) Near real-time agriculture monitoring at national scale at parcel resolution: performance assessment of the Sen2-Agri automated system in various cropping systems around the world. Remote Sens Environ 221:551-568. https://doi.org/10.1016/j.rse. 2018.11.007

de Alban J, Connette G, Oswald P, Webb E (2018) Combined Landsat and L-band SAR data improves land cover classification and change detection in dynamic tropical landscapes. Remote Sens 10:306. https://doi.org/10.3390/rs10020306

Delincé J (ed) (2017) Handbook of the global strategy to improve agricultural and rural statistics (GSARS), Rome

Dheeravath V, Thenkabail PS, Chandrakantha G, Noojipady P, Reddy GPO, Biradar CM, Gumma MK, Velpuri M (2010) Irrigated areas of India derived using MODIS $500 \mathrm{~m}$ time series for the years 2001 2003. ISPRS J Photogramm 65:42-59. https://doi.org/10.1016/j. isprsjprs.2009.08.004

Donaldson D, Storeygard A (2016) The view from above: applications of satellite data in economics. J Econ Perspect 30:171-198. https://doi. org/10.1257/jep.30.4.171

Doss CR (2006) Analyzing technology adoption using microstudies: limitations, challenges, and opportunities for improvement. Agric Econ 34:207-219. https://doi.org/10.1111/j.1574-0864.2006.00119.x

Eckert S, Tesfay Ghebremicael S, Hurni H, Kohler T (2017) Identification and classification of structural soil conservation measures based on very high resolution stereo satellite data. J Environ Manag 193:592-606. https://doi.org/10.1016/j.jenvman.2017.02. 061

Engstrom R, Hersh JS, Newhouse D (2017) Poverty from space: using high-resolution satellite imagery for estimating economic well-being. Policy Research Working Paper 2017(8284). Accessed 18 June 2018

Evenson RE, Gollin D (2003) Assessing the impact of the green revolution, 1960 to 2000. Science 300:758-762. https://doi.org/10.1126/ science. 1078710

Fang H, Wu B, Liu H, Huang X (1998) Using NOAA AVHRR and Landsat TM to estimate rice area year-by-year. Int J Remote Sens 19:521-525. https://doi.org/10.1080/014311698216134

Fernández-Quintanilla C, Peña JM, Andújar D, Dorado J, Ribeiro A, López-Granados F (2018) Is the current state of the art of weed monitoring suitable for site-specific weed management in arable crops? Weed Res 58:259-272. https://doi.org/10.1111/wre.12307

Frappart F, Ramillien G (2018) Monitoring groundwater storage changes using the gravity recovery and climate experiment (GRACE) 
satellite mission: a review. Remote Sens 10:829. https://doi.org/10. $3390 /$ rs 10060829

Funk C, Budde ME (2009) Phenologically-tuned MODIS NDVI-based production anomaly estimates for Zimbabwe. Remote Sens Environ 113:115-125. https://doi.org/10.1016/j.rse.2008.08.015

Giglio L, Schroeder W, Justice CO (2016) The collection 6 MODIS active fire detection algorithm and fire products. Remote Sens Environ 178:31-41. https://doi.org/10.1016/j.rse.2016.02.054

Gómez C, White JC, Wulder MA (2016) Optical remotely sensed time series data for land cover classification: a review. ISPRS J Photogramm 116:55-72. https://doi.org/10.1016/j.isprsjprs.2016. 03.008

Gray J, Friedl M, Frolking S, Ramankutty N, Nelson A, Gumma MK (2014) Mapping Asian cropping intensity with MODIS. IEEE J Sel Top Appl Earth Observations Remote Sensing 7:3373-3379. https:// doi.org/10.1109/JSTARS.2014.2344630

Gregory PJ, Ingram JSI, Andersson R, Betts RA, Brovkin V, Chase TN, Grace PR, Gray AJ, Hamilton N, Hardy TB, Howden SM, Jenkins A, Meybeck M, Olsson M, Ortiz-Monasterio I, Palm CA, Payn TW, Rummukainen M, Schulze RE, Thiem M, Valentin C, Wilkinson MJ (2002) Environmental consequences of alternative practices for intensifying crop production. Agric Ecosyst Environ 88:279-290. https://doi.org/10.1016/S0167-8809(01)00263-8

Gumma MK, Thenkabail PS, Hideto F, Nelson A, Dheeravath V, Busia D, Rala A (2011) Mapping irrigated areas of Ghana using fusion of $30 \mathrm{~m}$ and $250 \mathrm{~m}$ resolution remote-sensing data. Remote Sens 3: 816-835. https://doi.org/10.3390/rs3040816

Hadria R, Duchemin B, Baup F, Le Toan T, Bouvet A, Dedieu G, Le Page M (2009) Combined use of optical and radar satellite data for the detection of tillage and irrigation operations: case study in Central Morocco. Agr Water Manage 96:1120-1127. https://doi.org/10. 1016/j.agwat.2009.02.010

Halleck Vega S, Elhorst JP (2015) The SLX model. J Reg Sci 55:339 363. https://doi.org/10.1111/jors. 12188

He M, Kimball J, Maneta M, Maxwell B, Moreno A, Beguería S, Wu X (2018) Regional crop gross primary productivity and yield estimation using fused Landsat-MODIS data. Remote Sens 10:372. https:// doi.org/10.3390/rs10030372

Head A, Manguin M, Tran N, Blumenstock JE (2017) Can human development be measured with satellite imagery? In: Saif U (ed) Proceedings of the ninth international conference on information and communication technologies and development. ACM, New York, NY, 1-11

Hillger D, Kopp T, Lee T, Lindsey D, Seaman C, Miller S, Solbrig J, Kidder S, Bachmeier S, Jasmin T, Rink T (2013) First-light imagery from Suomi NPP VIIRS. Bull Amer Meteor Soc 94:1019-1029. https://doi.org/10.1175/BAMS-D-12-00097.1

Hobbs PR, Sayre K, Gupta R (2008) The role of conservation agriculture in sustainable agriculture. Philos Trans R Soc Lond B Biol Sci 363: 543-555. https://doi.org/10.1098/rstb.2007.2169

Holden ST, Fisher M (2013) Can area measurement error explain the inverse farm size productivity relationship? CLTS Working paper (12). Accessed 2 July 2018

Huang Q, Yang X, Gao B, Yang Y, Zhao Y (2014) Application of DMSP/OLS nighttime light images: a meta-analysis and a systematic literature review. Remote Sens 6:6844-6866. https://doi.org/10. 3390/rs6086844

Hurley TM, Rao X, Pardey PG (2014) Re-examining the reported rates of return to food and agricultural research and development. Am J Agric Econ 96:1492-1504. https://doi.org/10.1093/ajae/aau047

Immitzer M, Vuolo F, Atzberger C (2016) First experience with Sentinel2 data for crop and tree species classifications in Central Europe. Remote Sens 8:166. https://doi.org/10.3390/rs8030166

Inglada J, Arias M, Tardy B, Hagolle O, Valero S, Morin D, Dedieu G, Sepulcre G, Bontemps S, Defourny P, Koetz B (2015) Assessment of an operational system for crop type map production using high temporal and spatial resolution satellite optical imagery. Remote Sens 7:12356-12379. https://doi.org/10.3390/rs70912356

Inglada J, Vincent A, Arias M, Marais-Sicre C (2016) Improved early crop type identification by joint use of high temporal resolution SAR and optical image time series. Remote Sens 8:362. https://doi.org/ $10.3390 / \mathrm{rs} 8050362$

Ioannidis JPA, Stanley TD, Doucouliagos H (2017) The power of bias in economics research. Econ J 127:236-265. https://doi.org/10.1111/ ecoj. 12461

Jain M, Mondal P, DeFries RS, Small C, Galford GL (2013) Mapping cropping intensity of smallholder farms: a comparison of methods using multiple sensors. Remote Sens Environ 134:210-223. https:// doi.org/10.1016/j.rse.2013.02.029

Jain M, Srivastava A, Balwinder-Singh JR, McDonald A, Royal K, Lisaius M, Lobell DB (2016) Mapping smallholder wheat yields and sowing dates using micro-satellite data. Remote Sens 8:860. https://doi.org/10.3390/rs8100860

Jain M, Mondal P, Galford G, Fiske G, DeFries R (2017a) An automated approach to map winter cropped area of smallholder farms across large scales using MODIS imagery. Remote Sens 9:566. https://doi. org/10.3390/rs9060566

Jain M, Singh B, Srivastava AAK, Malik RK, McDonald AJ, Lobell DB (2017b) Using satellite data to identify the causes of and potential solutions for yield gaps in India's Wheat Belt. Environ Res Lett 12: 94011. https://doi.org/10.1088/1748-9326/aa8228

Jean N, Burke M, Xie M, Davis WM, Lobell DB, Ermon S (2016) Combining satellite imagery and machine learning to predict poverty. Science 353:790-794. https://doi.org/10.1126/science.aaf7894

Jensen ME, Allen RG (2016) Evaporation, evapotranspiration, and irrigation water requirements. American Society of Civil Engineers, Reston, VA

Ji S, Zhang C, Xu A, Shi Y, Duan Y (2018) 3D convolutional neural networks for crop classification with multi-temporal remote sensing images. Remote Sens 10:75. https://doi.org/10.3390/rs10010075

Jin Z, Azzari G, Burke M, Aston S, Lobell DB (2017) Mapping smallholder yield heterogeneity at multiple scales in Eastern Africa. Remote Sens 9:931. https://doi.org/10.3390/rs9090931

Kamau M, Smale M, Mutua M (2014) Farmer demand for soil fertility management practices in Kenya's grain basket. Food Sec 6:793806. https://doi.org/10.1007/s12571-014-0398-5

Kamthonkiat D, Honda K, Turral HN, Tripathi NK, Wuwongse V (2007) Discrimination of irrigated and rainfed rice in a tropical agricultural system using SPOT VEGETATION NDVI and rainfall data. Int J Remote Sens 26:2527-2547. https://doi.org/10.1080/ 01431160500104335

Kaskaoutis DG, Kumar S, Sharma D, Singh RP, Kharol SK, Sharma M, Singh AK, Singh S, Singh A, Singh D (2014) Effects of crop residue burning on aerosol properties, plume characteristics, and long-range transport over northern India. J Geophys Res Atmos 119:5424 5444. https://doi.org/10.1002/2013JD021357

Kastens JH, Brown JC, Coutinho AC, Bishop CR, Esquerdo JCDM (2017) Soy moratorium impacts on soybean and deforestation dynamics in Mato Grosso, Brazil. PLoS One 12:e0176168. https://doi. org/10.1371/journal.pone.0176168

Keola S, Andersson M, Hall O (2015) Monitoring economic development from space: using nighttime light and land cover data to measure economic growth. World Dev 66:322-334. https://doi.org/10. 1016/j.worlddev.2014.08.017

Khanal S, Fulton J, Klopfenstein A, Douridas N, Shearer S (2018) Integration of high resolution remotely sensed data and machine learning techniques for spatial prediction of soil properties and corn yield. Comput Electron Agric 153:213-225. https://doi.org/10. 1016/j.compag.2018.07.016

Knowler D, Bradshaw B (2007) Farmers' adoption of conservation agriculture: a review and synthesis of recent research. Food Policy 32: 25-48. https://doi.org/10.1016/j.foodpol.2006.01.003 
Kosmowski F, Stevenson J, Campbell J, Ambel A, Haile Tsegay A (2017) On the ground or in the air? A methodological experiment on crop residue cover measurement in Ethiopia. Environ Manag 60:705716. https://doi.org/10.1007/s00267-017-0898-0

Krishna VV, Veettil PC (2014) Productivity and efficiency impacts of conservation tillage in northwest Indo-Gangetic Plains. Agric Syst 127:126-138. https://doi.org/10.1016/j.agsy.2014.02.004

Kubitza C, Krishna VV, Urban K, Alamsyah Z, Qaim M (2018) Land property rights, agricultural intensification, and deforestation in Indonesia. Ecol Econ 147:312-321. https://doi.org/10.1016/j. ecolecon.2018.01.021

Kussul N, Lavreniuk M, Skakun S, Shelestov A (2017) Deep learning classification of land cover and crop types using remote sensing data. IEEE Geosci Remote Sensing Lett 14:778-782. https://doi. org/10.1109/LGRS.2017.2681128

Labus MP, Nielsen GA, Lawrence RL, Engel R, Long DS (2010) Wheat yield estimates using multi-temporal NDVI satellite imagery. Int $\mathrm{J}$ Remote Sens 23:4169-4180. https://doi.org/10.1080/ 01431160110107653

Lambert M-J, Traoré PCS, Blaes X, Baret P, Defourny P (2018) Estimating smallholder crops production at village level from Sentinel-2 time series in Mali's cotton belt. Remote Sens Environ 216:647-657. https://doi.org/10.1016/j.rse.2018.06.036

Lasko K, Vadrevu KP, Tran VT, Justice C (2018) Mapping double and single crop paddy rice with Sentinel-1A at varying spatial scales and polarizations in Hanoi, Vietnam. IEEE J Sel Top Appl Earth Observations Remote Sensing 11:498-512. https://doi.org/10. 1109/JSTARS.2017.2784784

Lebourgeois V, Dupuy S, Vintrou É, Ameline M, Butler S, Bégué A (2017) A combined random forest and OBIA classification scheme for mapping smallholder agriculture at different nomenclature levels using multisource data (simulated Sentinel-2 time series, VHRS and DEM). Remote Sens 9:259. https://doi.org/10.3390/rs9030259

Lelieveld J, Evans JS, Fnais M, Giannadaki D, Pozzer A (2015) The contribution of outdoor air pollution sources to premature mortality on a global scale. Nature 525:367-371. https://doi.org/10.1038/ nature 15371

LeSage JP, Pace RK (2009) Introduction to spatial econometrics. Statistics, textbooks and monographs, vol 196. CRC press, Boca Raton

Li S, Sun D, Goldberg MD, Sjoberg B, Santek D, Hoffman JP, DeWeese M, Restrepo P, Lindsey S, Holloway E (2018) Automatic near realtime flood detection using Suomi-NPP/VIIRS data. Remote Sens Environ 204:672-689. https://doi.org/10.1016/j.rse.2017.09.032

Liu X, He B, Quan X, Yebra M, Qiu S, Yin C, Liao Z, Zhang H (2018a) Near real-time extracting wildfire spread rate from Himawari- 8 satellite data. Remote Sens 10:1654. https://doi.org/10.3390/ rs10101654

Liu T, Marlier ME, DeFries RS, Westervelt DM, Xia KR, Fiore AM, Mickley LJ, Cusworth DH, Milly G (2018b) Seasonal impact of regional outdoor biomass burning on air pollution in three Indian cities: Delhi, Bengaluru, and Pune. Atmos Environ 172:83-92. https://doi.org/10.1016/j.atmosenv.2017.10.024

Lobell DB, Azzari G (2017) Satellite detection of rising maize yield heterogeneity in the U.S. Midwest. Environ Res Lett 12:14014. https://doi.org/10.1088/1748-9326/aa5371

Lobell DB, Asner GP, Ortiz-Monasterio JI, Benning TL (2003) Remote sensing of regional crop production in the Yaqui Valley, Mexico: estimates and uncertainties. Agric Ecosyst Environ 94:205-220. https://doi.org/10.1016/S0167-8809(02)00021-X

Lobell DB, Ortiz-Monasterio JI, Sibley AM, Sohu VS (2013) Satellite detection of earlier wheat sowing in India and implications for yield trends. Agric Syst 115:137-143. https://doi.org/10.1016/j.agsy. 2012.09.003
Lobell DB, Thau D, Seifert CA, Engle E, Little B (2015) A scalable satellite-based crop yield mapper. Remote Sens Environ 164:324 333. https://doi.org/10.1016/j.rse.2015.04.021

Lobell DB, Azzari G, Burke M, Gourlay S, Jin Z, Kilic T, Murray S (2018) Eyes in the sky, boots on the ground: assessing satelliteand ground-based approaches to crop yield measurement and analysis in Uganda. Policy Research Working Paper (8374). Accessed 18 June 2018

Mondal P, Jain M, Zukowski M, Galford G, DeFries R (2016) Quantifying fluctuations in winter productive cropped area in the Central Indian Highlands. Reg Environ Chang 16:69-82. https:// doi.org/10.1007/s10113-016-0946-y

Mutenje M, Kankwamba H, Mangisonib J, Kassie M (2016) Agricultural innovations and food security in Malawi: gender dynamics, institutions and market implications. Technol Forecast Soc 103:240-248. https://doi.org/10.1016/j.techfore.2015.10.004

Nasrallah A, Baghdadi N, Mhawej M, Faour G, Darwish T, Belhouchette H, Darwich S (2018) A novel approach for mapping wheat areas using high resolution Sentinel-2 images. Sensors 18. https://doi.org/ $10.3390 / \mathrm{s} 18072089$

Ortiz-Monasterio JI, Lobell DB (2007) Remote sensing assessment of regional yield losses due to sub-optimal planting dates and fallow period weed management. Field Crop Res 101:80-87. https://doi. org/10.1016/j.fcr.2006.09.012

Peña MA, Brenning A (2015) Assessing fruit-tree crop classification from Landsat-8 time series for the Maipo Valley, Chile. Remote Sens Environ 171:234-244. https://doi.org/10.1016/j.rse.2015.10. 029

Pittelkow CM, Liang X, Linquist BA, van Groenigen KJ, Lee J, Lundy ME, van Gestel N, Six J, Venterea RT, van Kessel C (2015) Productivity limits and potentials of the principles of conservation agriculture. Nature 517:365-368. https://doi.org/10.1038/ nature 13809

Pray CE, Masters W, Ayoub S (2017) Impacts of agricultural research on poverty, malnutrition and resilience. Report for USAID/Bureau for Food Security, Office of Agriculture, Research and Policy. Accessed 18 October 2018

Quemada M, Daughtry C (2016) Spectral indices to improve crop residue cover estimation under varying moisture conditions. Remote Sens 8: 660. https://doi.org/10.3390/rs8080660

Quemada M, Hively WD, Daughtry CST, Lamb BT, Shermeyer J (2018) Improved crop residue cover estimates obtained by coupling spectral indices for residue and moisture. Remote Sens Environ 206:3344. https://doi.org/10.1016/j.rse.2017.12.012

Raitzer DA, Maredia MK (2012) Analysis of agricultural research investment priorities for sustainable poverty reduction in Southeast Asia. Food Policy 37:412-426. https://doi.org/10.1016/j.foodpol.2012. 04.001

Richards DR, Friess DA (2016) Rates and drivers of mangrove deforestation in Southeast Asia, 2000-2012. Proc Natl Acad Sci U S A 113: 344-349. https://doi.org/10.1073/pnas.1510272113

Román MO, Wang Z, Sun Q, Kalb V, Miller SD, Molthan A, Schultz L, Bell J, Stokes EC, Pandey B, Seto KC, Hall D, Oda T, Wolfe RE, Lin G, Golpayegani N, Devadiga S, Davidson C, Sarkar S, Praderas C, Schmaltz J, Boller R, Stevens J, Ramos González OM, Padilla E, Alonso J, Detrés Y, Armstrong R, Miranda I, Conte Y, Marrero N, MacManus K, Esch T, Masuoka EJ (2018) NASA's Black Marble nighttime lights product suite. Remote Sens Environ 210:113-143. https://doi.org/10.1016/j.rse.2018.03.017

Rufin P, Levers C, Baumann M, Jägermeyr J, Krueger T, Kuemmerle T, Hostert P (2018) Global-scale patterns and determinants of cropping frequency in irrigation dam command areas. Glob Environ Chang 50:110-122. https://doi.org/10.1016/j.gloenvcha.2018.02.011

Schulthess U, Timsina J, Herrera JM, McDonald A (2013) Mapping fieldscale yield gaps for maize: an example from Bangladesh. Field Crop Res 143:151-156. https://doi.org/10.1016/j.fcr.2012.11.004 
Shanwad UK, Patil VC, Honne Gowda H, Dasog GS (2008) Application of remote sensing technology for impact assessment of watershed development programme. J Indian Soc Remote 36:375-386. https:// doi.org/10.1007/s12524-008-0037-8

Singha M, Wu B, Zhang M (2016) An object-based paddy rice classification using multi-spectral data and crop phenology in Assam, Northeast India. Remote Sens 8:479. https://doi.org/10.3390/ rs 8060479

Skakun S, Justice CO, Vermote E, Roger J-C (2017) Transitioning from MODIS to VIIRS: an analysis of inter-consistency of NDVI data sets for agricultural monitoring. Int J Remote Sens 39:971-992. https://doi.org/10.1080/01431161.2017.1395970

Son N-T, Chen C-F, Chen C-R, Duc H-N, Chang L-Y (2014) A phenology-based classification of time-series MODIS data for rice crop monitoring in Mekong Delta, Vietnam. Remote Sens 6:135156. https://doi.org/10.3390/rs6010135

Strobl E, Strobl RO (2011) The distributional impact of large dams: evidence from cropland productivity in Africa. J Dev Econ 96: 432-450. https://doi.org/10.1016/j.jdeveco.2010.08.005

Thenkabail PS, Schull MA, Turral HN (2005) Ganges and Indus river basin land use/land cover (LULC) and irrigated area mapping using continuous streams of MODIS data. Remote Sens Environ 95:317341. https://doi.org/10.1016/j.rse.2004.12.018

Thenkabail PS, Biradar CM, Noojipady P, Dheeravath V, Li Y, Velpuri M, Gumma MK, Gangalakunta ORP, Turral HN, Cai X, Vithanage J, Schull MA, Dutta R (2009) Global irrigated area map (GIAM), derived from remote sensing, for the end of the last millennium. Int J Remote Sens 30:3679-3733. https://doi.org/10.1080/ 01431160802698919

Toomanian N, Gieske ASM, Akbary M (2010) Irrigated area determination by NOAA-Landsat upscaling techniques, Zayandeh river basin, Isfahan, Iran. Int J Remote Sens 25:4945-4960. https://oi.org/10. 1080/01431160410001713007

Tso B, Mather PM (2009) Classification methods for remotely sensed data, 2nd edn. CRC Press, Boca Raton, FL

Tsusaka TW, Kajisa K, Pede VO, Aoyagi K (2015) Neighborhood effects and social behavior: the case of irrigated and rainfed farmers in Bohol, the Philippines. J Econ Behav Organ 118:227-246. https:// doi.org/10.1016/j.jebo.2015.04.022

Vågen T-G, Winowiecki LA, Tondoh JE, Desta LT, Gumbricht T (2016) Mapping of soil properties and land degradation risk in Africa using MODIS reflectance. Geoderma 263:216-225. https://doi.org/10. 1016/j.geoderma.2015.06.023

Vijayakumar K, Safai PD, Devara PCS, Rao SVB, Jayasankar CK (2016) Effects of agriculture crop residue burning on aerosol properties and long-range transport over northern India: a study using satellite data and model simulations. Atmos Res 178-179:155-163. https://doi. org/10.1016/j.atmosres.2016.04.003

Vuolo F, Neuwirth M, Immitzer M, Atzberger C, Ng W-T (2018) How much does multi-temporal Sentinel-2 data improve crop type classification? Int J Appl Earth Obs 72:122-130. https://doi.org/10. 1016/j.jag.2018.06.007

Wallander S, Bowman M, Beeson P, Claassen R (2018) Farmers and habits: the challenge of identifying the sources of persistence in tillage decisions. ASSA Annual Meeting. Accessed 15 June 2018

Wang J, Huang J, Zhang K, Li X, She B, Wei C, Gao J, Song X (2015) Rice fields mapping in fragmented area using multi-temporal HJ-
1A/B CCD images. Remote Sens 7:3467-3488. https://doi.org/10. 3390/rs70403467

Wang S, Baig MHA, Liu S, Wan H, Wu T, Yang Y (2018) Estimating the area burned by agricultural fires from Landsat 8 Data using the Vegetation Difference Index and Burn Scar Index. Int J Wildland Fire 27:217-227. https://doi.org/10.1071/WF17069

Wang CK, Li ZT, Pan XZ (2017) Estimating crop residue cover using SPOT 5 data. J Soil Water Conserv 72:343-350. https://doi.org/10. 2489/jswc.72.4.343

Wickama J, Masselink R, Sterk G (2015) The effectiveness of soil conservation measures at a landscape scale in the West Usambara highlands, Tanzania. Geoderma 241-242:168-179. https://doi.org/10. 1016/j.geoderma.2014.11.020

Wilken F, Wagner PD, Narasimhan B, Fiener P (2017) Spatio-temporal patterns of land use and cropping frequency in a tropical catchment of South India. Appl Geogr 89:124-132. https://doi.org/10.1016/j. apgeog.2017.10.011

Wollni M, Andersson C (2014) Spatial patterns of organic agriculture adoption: evidence from Honduras. Ecol Econ 97:120-128. https://doi.org/10.1016/j.ecolecon.2013.11.010

Wu R, Yang D, Dong J, Zhang L, Xia F (2018) Regional inequality in China based on NPP-VIIRS night-time light imagery. Remote Sens 10:240-259. https://doi.org/10.3390/rs10020240

Yamamoto Y, Oberthür T, Lefroy R (2009) Spatial identification by satellite imagery of the crop-fallow rotation cycle in northern Laos. Environ Dev Sustain 11:639-654. https://doi.org/10.1007/s10668007-9134-z

Yan H, Xiao X, Huang H, Liu J, Chen J, Bai X (2014) Multiple cropping intensity in China derived from agro-meteorological observations and MODIS data. Chin Geogr Sci 24:205-219. https://doi.org/10. 1007/s11769-013-0637-2

Yonah IB, Mourice SK, Tumbo SD, Mbilinyi BP, Dempewolf J (2018) Unmanned aerial vehicle-based remote sensing in monitoring smallholder, heterogeneous crop fields in Tanzania. Int J Remote Sens 39: 5453-5471. https://doi.org/10.1080/01431161.2018.1455241

Zhang M, Lin H, Wang G, Sun H, Fu J (2018) Mapping paddy rice using a convolutional neural network (CNN) with Landsat 8 datasets in the Dongting Lake Area, China. Remote Sens 10:1840. https://doi.org/ $10.3390 /$ rs 10111840

Zhao Q, Brocks S, Lenz-Wiedemann VIS, Miao Y, Zhang F, Bareth G (2017) Detecting spatial variability of paddy rice yield by combining the DNDC model with high resolution satellite images. Agric Syst 152:47-57. https://doi.org/10.1016/j.agsy.2016.11.011

Zheng B, Campbell JB, de Beurs KM (2012) Remote sensing of crop residue cover using multi-temporal Landsat imagery. Remote Sens Environ 117:177-183. https://doi.org/10.1016/j.rse.2011.09.016

Zheng B, Campbell JB, Serbin G, Galbraith JM (2014) Remote sensing of crop residue and tillage practices: present capabilities and future prospects. Soil Tillage Res 138:26-34. https://doi.org/10.1016/j. still.2013.12.009

Zhu XX, Tuia D, Mou L, Xia G-S, Zhang L, Xu F, Fraundorfer F (2017) Deep learning in remote sensing: a comprehensive review and list of resources. IEEE Geosci Remote Sens Mag 5:8-36. https://doi.org/ 10.1109/MGRS.2017.2762307

Publisher's note Springer Nature remains neutral with regard to jurisdictional claims in published maps and institutional affiliations. 